This item was submitted to Loughborough's Research Repository by the author.

Items in Figshare are protected by copyright, with all rights reserved, unless otherwise indicated.

\title{
Industry fragmentation and wastewater efficiency: A case study of hyogo prefecture in Japan
}

\section{PLEASE CITE THE PUBLISHED VERSION}

https://www.adb.org/publications/industry-fragmentation-wastewater-efficiency-hyogo-japan

\section{PUBLISHER}

Asian Development Bank Institute

\section{VERSION}

VoR (Version of Record)

\section{PUBLISHER STATEMENT}

This is an Open Access Article. It is published by Asian Development Bank Institute under the Creative Commons Attribution-NonCommercial-NoDerivatives 4.0 International (CC BY-NC-ND 4.0) licence. Full details of this licence are available at: https://creativecommons.org/licenses/by-nc-nd/4.0/

\section{LICENCE}

CC BY-NC-ND 4.0

\section{REPOSITORY RECORD}

Urakami, Takuya, David Saal, and Maria Nieswand. 2021. "Industry Fragmentation and Wastewater Efficiency: A Case Study of Hyogo Prefecture in Japan". Loughborough University. https://hdl.handle.net/2134/14199602.v1. 


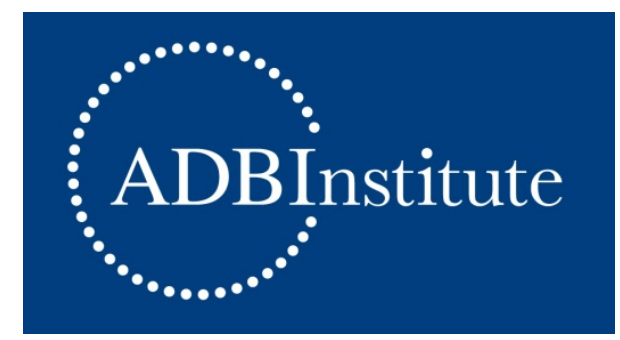

ADBI Working Paper Series

INDUSTRY FRAGMENTATION

AND WASTEWATER EFFICIENCY:

A CASE STUDY OF HYOGO

PREFECTURE IN JAPAN

Takuya Urakami, David S. Saal, and Maria Nieswand

No. 1218

February 2021

\section{Asian Development Bank Institute}


Takuya Urakami is a Professor at the Faculty of Business Administration, Kindai University, Japan. David S. Saal is a Professor at the School of Business and Economics, Loughborough University, United Kingdom. Maria Nieswand is an Assistant Professor at the School of Business and Economics, Loughborough University, United Kingdom.

The views expressed in this paper are the views of the author and do not necessarily reflect the views or policies of $A D B I, A D B$, its Board of Directors, or the governments they represent. $\mathrm{ADBI}$ does not guarantee the accuracy of the data included in this paper and accepts no responsibility for any consequences of their use. Terminology used may not necessarily be consistent with ADB official terms.

Working papers are subject to formal revision and correction before they are finalized and considered published.

The Working Paper series is a continuation of the formerly named Discussion Paper series; the numbering of the papers continued without interruption or change. ADBI's working papers reflect initial ideas on a topic and are posted online for discussion. Some working papers may develop into other forms of publication.

\section{Suggested citation:}

Urakami, T., D. S. Saal, and M. Nieswand. 2021. Industry Fragmentation and Wastewater Efficiency: A Case Study of Hyogo Prefecture in Japan. ADBI Working Paper 1218. Tokyo: Asian Development Bank Institute. Available: https://www.adb.org/publications/industryfragmentation-wastewater-efficiency-hyogo-japan

Please contact the authors for information about this paper.

Email: urakami@bus.kindai.ac.jp

This research is conducted as a part of the GAIA Project (Gesuido Academic Incubation to Advanced Project), which is supported by MLIT.

Asian Development Bank Institute Kasumigaseki Building, 8th Floor 3-2-5 Kasumigaseki, Chiyoda-ku Tokyo 100-6008, Japan

Tel: $\quad+81-3-3593-5500$

Fax: $\quad+81-3-3593-5571$

URL: $\quad$ www.adbi.org

E-mail: info@adbi.org

(C) 2021 Asian Development Bank Institute 


\begin{abstract}
The efficient operation of sewerage services is impacted by various factors such as geographical and topographical conditions, diversity of vertical and horizontal organizational structure, ownership types, and level of public-private partnership. The Ministry of Land, Infrastructure, Transport and Tourism, as the primary regulator of the sewerage industry in Japan, has conducted policy reforms to address issues facing the country in the 21st century: population decline, aging population, potentially high investment needs due to the aging facilities and frequent natural disasters, and fiscal pressures given the country's high debt to gross domestic product ratio. The ministry has set out several policy directions, with the most important being wide-area consolidation (WAC). Given the fragmented nature of Japan's municipally controlled sewerage system with different entities serving different customer types, the optimal consolidation strategy might differ both within and between Japan's 47 prefectures. We therefore conducted a case study of Hyogo Prefecture, which has identified several subprefecture regions within which to pursue WAC. Our aim was to gain a better understanding of how the complex characteristics and fragmentation impact not only current sewerage entity performance, but also the required approach to achieve the benefits from WAC. We argue that WAC policy objectives would be best achieved by establishing consolidated regional public sewer authorities, which should adopt one of the following consolidation strategies, depending on their own characteristics: consolidation to improve operational performance without physical integration; consolidation around a non-urban river basin system to improve treatment and collection efficiency; consolidation around a regional champion city to support small municipalities; consolidation around an urban river basin system of all operations and infrastructure; and urban consolidation of operations, collection, and treatment infrastructure.
\end{abstract}

Keywords: wide area consolidation, case study, Japanese sewerage industry

JEL Classification: L22, L25, L95 


\section{Contents}

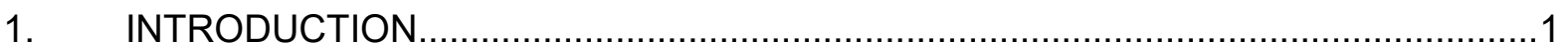

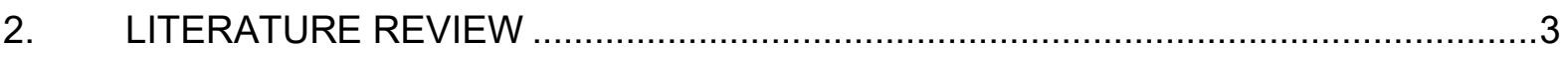

3. A BRIEF HISTORY AND THE STRUCTURE OF THE SEWERAGE SECTOR .........6

4. DIRECTION OF THE GOVERNMENT'S POLICY REFORM ................................

5. CASE STUDY: HYOGO PREFECTURE ..................................................11

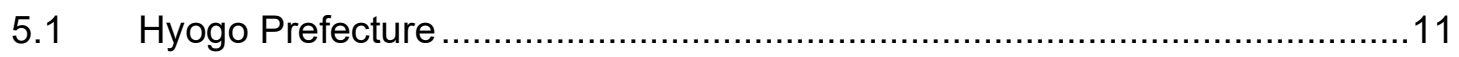

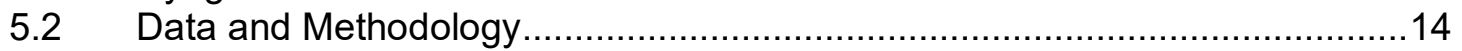

5.3 Characterizing the Proposed Wide-Area Consolidation Regions ...................15

5.4 Identifying Objectives for the Proposed WAC Regions..................................18

6. DISCUSSION OF PROPOSED PUBLIC SEWER AUTHORITIES TO IMPLEMENT

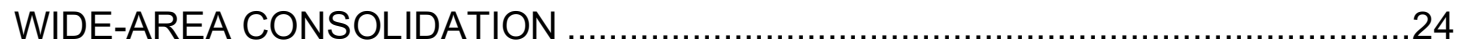

7. SUMMARY AND FUTURE RESEARCH TO INFORM WIDE-AREA

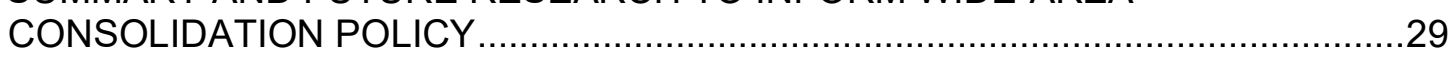

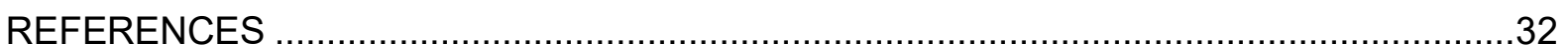




\section{INTRODUCTION}

Japan's modern sewerage works began to be established almost 130 years ago, mainly in large cities and with the primary purpose to stop rainwater flooding and to prevent the outbreak of infectious diseases caused by residual insanitary water. At the same time, water suppliers were also established to secure public health and to prevent fires. However, while the public provision of water rapidly expanded during Japan's postwar high economic growth period, public sewerage systems were expanded at a much slower rate.

As a result, while $96.6 \%$ of the population were connected to public water supply, the penetration ratio of the public sewerage system was only $62.0 \%$ in fiscal year (FY) 2000 . By the end of FY2016, the penetration ratio had improved to around $80 \%$ for those with public sewerage service-and $90 \%$ if we also include those using public or private Johkasou-based treatment. ${ }^{1}$ Nevertheless, both the trend and penetration level for piped water and sewerage services differ considerably in Japan (Figure 1). Given the still relatively low penetration of public sewerage services, as well as the onset of rapidly increasing population decline, the sewerage sector faces considerable challenges. In response, the Ministry of Land, Infrastructure, Transport and Tourism (MLIT) is considering several policies to address various issues, including wide area consolidation (WAC) and the sharing of facilities.

Figure 1: Trend of Coverage Ratio of Water and Sewerage

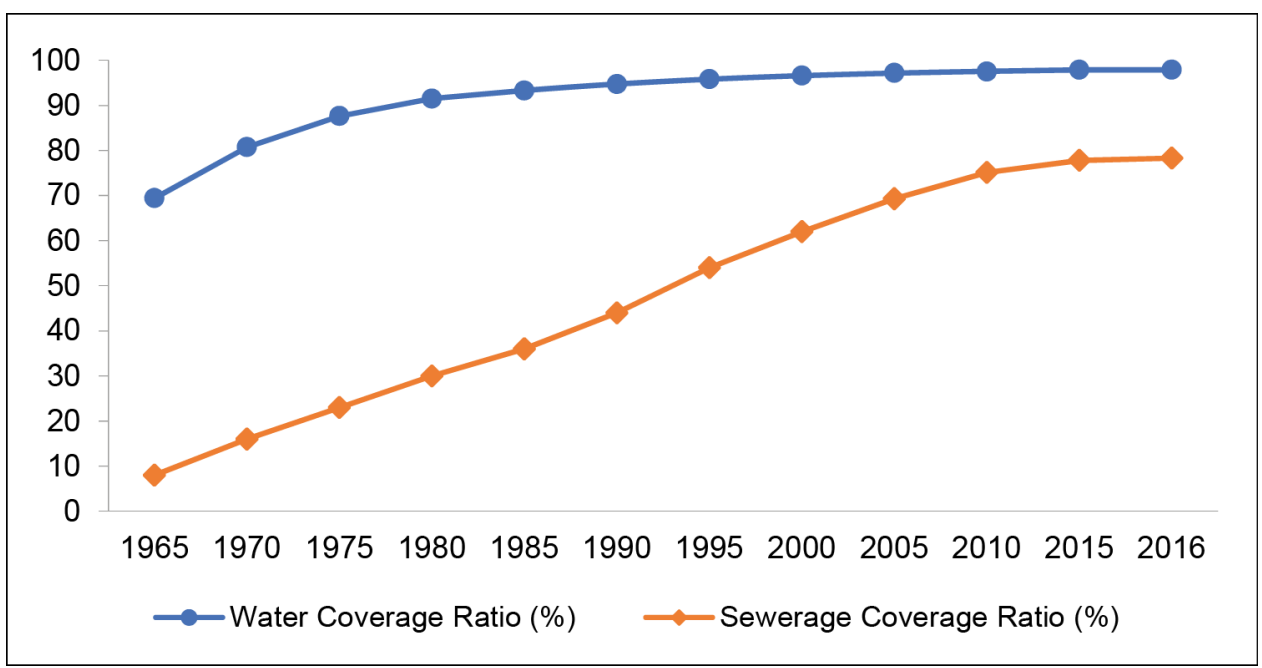

Source: Japan Waterworks Association, Ministry of Land, Infrastructure and Transport

From an academic point of view, sewerage research in Japan has mainly focused on natural science and engineering-related aspects, such as civil engineering, sanitary engineering, and microbiology. Studies in other countries have looked at the economic impacts on productivity, efficiency, performance, and so on (Knapp 1978; Renzetti 1999; Fraas and Munley 1984; Blaeschke and Haug 2018; Fraquelli and Giandrone 2003; Hernández-Sancho, Molinos-Senante, and Sala-Garrido 2011; Molinos-Senante, Hernández-Sancho, and Sala-Garrido 2014; Molinos-Senante et al. 2016; Guerrini

\footnotetext{
1 Johkasou is a kind of on-site independent sewage treatment system in rural areas promoted by the Japanese Ministry of the Environment (MOE). Details of the Johkasou septic tank system are introduced on MOE webpage (https://www.env.go.jp/recycle/jokaso/en/).
} 
et al. 2015, 2016; Fuentes, Torregrosa-Martí, and Hernández-Sancho 2017; CastelletViciano, Torregrossa, and Hernández-Sancho 2018). However, most of these studies have been conducted at the sewage plant level, not at the level of true decision-making, which is at the level of the integrated operating utility.

In Japan, as in many other countries, municipalities own and operate whole sewerage systems including wastewater collection, wastewater treatment, and sludge treatment and disposal, so decision-making is at the municipal level. Moreover, it is common for these decision-making units to operate multiple sewerage collection and treatment systems within their municipal boundaries. However, as we will elaborate later, Japan differs from most countries because municipalities, within their boundaries, operate multiple sewage entities, which not only serve different types of customers and/or operating areas but also are being regulated by different government ministries. Moreover, Japan also differs from many countries because in locations served by its treatment only municipalities with river basin systems (RBSs) have the option to have all or part of their sewage treatment carried out by such a system. Thus, Japanese municipal sewerage systems will differ considerably regarding not only the degree to which they can or do rely on externally operated sewage treatment facilities, but also the degree to which they rely on different sewerage entity types to collect and treat sewage.

Another important aspect of Japan's sewerage industry is the impact of the Great Heisei Era Consolidation (Heisei no Daigappei) when the Cabinet Office of Japan promoted the consolidation of municipal governments during the Heisei era (the reign of Emperor Akihito from 1989 to 2019). As a result, the number of local governments declined from 3,229 to 1,718 between 1999 and 2014, with the vast majority of municipal mergers occurring in 2004 and 2005. Since municipalities own and operate sewerage utilities, their number correspondingly decreased from 4,539 in 1999 to 3,639 in 2016. Although previous studies have analyzed the economic impacts of this municipal consolidation on the water sector (Urakami and Parker 2011; Arocena et al. 2020), there are no studies yet of its impact on the Japanese sewerage sector.

The continued improvement and resilience of sewerage services in Japan necessitates appropriate sewerage management and the proper maintenance of facilities. This is because Japan faces three main difficulties in the 21st century: potentially high investment needs; fiscal pressures; and rapid population decline coupled with an aging population. First, most infrastructure in Japan's urban areas was constructed in the economic growth period between the 1960s and 1980s, and these facilities are now aging. The replacement cost is therefore expected to increase in the future. Furthermore, frequent natural disasters such as earthquakes, typhoons, and heavy rains have occurred in Japan, requiring more investment to prevent or decrease potential damage from such disasters. Second, the debt to gross domestic product (GDP) ratio of Japan in 2019 was $238 \%$, which is highest among the Group of Twenty (G20) countries (90.4\% on average among the other 19 countries) (International Monetary Fund 2020). This fiscal constraint means both that more cost-effective management is required and that continuation of past policies that subsidized investment needs may not be feasible. Finally, the total population in Japan reached a peak in 2008 and is now decreasingand the population is aging. These changes in social structure have especially impacted infrastructure in Japan. In the case of the sewerage industry, the demographic changes are leading to a continued decline in customer numbers and revenue, as well as to problems of technology succession and the lack of available technical staff. 
As the impact of these issues on the sewerage industry can only be addressed by understanding and improving the operations under the control of decision-makers, this study necessarily focuses on detailing the relevant operating characteristics at the municipal level where current decision-making takes place in Japan. Nevertheless, as the underlying logic of MLIT's WAC initiatives imply, our case study of Hyogo Prefecture concludes that decision-making will need to be consolidated above the municipal level if policy makers truly wish to improve the cost-effectiveness and performance of Japan's sewerage sector. ${ }^{2}$

This paper is structured as follows. In section 2, we review the literature on benchmarking in the sewerage sector and then outline a brief history and details of the industry structure of the Japanese sewerage sector in section 3 . In section 4 , we explain the direction of government policy reform, followed in section 5 by a case study of Hyogo Prefecture. Our justification for proposing regional public sewerage authorities (PSAs) to implement WAC is further discussed in section 6, before section 7 finally presents a summary and suggestions for necessary further research to inform WAC policies.

\section{LITERATURE REVIEW}

While many previous studies have conducted benchmarking analysis of the water sector, or of integrated water and sewerage companies, few focus solely on the sewerage sector. The most important reason for this appears to be that water and sewerage systems are generally operated within a single company or government-run entity. Thus, Carvalho, Marques, and Berg (2012) highlighted that water and sewerage services in 17 of the 21 countries and regions considered were integrated or mostly integrated. Further, while Saal et al. (2013) surveyed a considerable number of studies analyzing economies of scale and scope in the water and wastewater industries, they emphasized that few studies focused on the analysis of cost functions and scale economies in the sewerage sector.

The situation is the same in Japan. Several empirical studies were conducted on the water sector (Aida et al. 1998; Mizutani and Urakami 2001; Urakami 2007, Urakami and Parker 2011; Nakamura, Urakami, and Kakamu 2019; Arocena et al. 2020; Liu and Fukushige 2020), but none on the sewage sector has been published internationally and only a few studies written in Japanese (Nakayama 2001; Terada 2003; Kobayashi et al. 2004). A possible reason is that the sewerage industry developed much later than water supply in Japan. New construction continued even in the 2000s, so priority was given to expanding sewerage services rather than economic efficiency. Another reason might be that the sewerage industry in Japan was more fragmented than the water industry, making it extremely difficult and time-consuming for economists to understand in-depth the characteristics of the sewerage sector. Nevertheless, we now turn to a brief review of those studies on the sewerage sector.

Saal et al. (2013) states that three pioneering studies analyzed the sewerage industry: two at the firm level (Knapp 1978; Renzetti 1999) and one at the treatment plant level (Fraas and Munley 1984). Knapp (1978) used a sample of sewerage works in England and Wales to estimate scale economies in the operation of sewage purification and treatment works. The results found that significant scale economies existed in the lower region of the observed output range (up to $16,600,000$ cubic meters annually of sewage

\footnotetext{
2 A preliminary version of this study was presented to MLIT as part of GAIA Project (Gesuido Academic Incubation to Advanced Project) Investigation Committee in February 2020.
} 
flow) but few thereafter. Renzetti (1999) analyzed Canadian water and sewerage utilities and estimated scale economies separately. He found that scale economies existed in both the water and sewerage sectors. Fraas and Munley (1984) used a sample of 178 wastewater treatment plants (WWTPs) in the United States and found that marginal costs decline remarkably with increases in the size of the waste flow, which suggested that scale economies existed in wastewater treatment.

Since these pioneering studies, several sewerage sector benchmarking studies have been conducted, but firm-level studies are still limited (Guerrini et al. 2015; Blaeschke and Haug 2018). In contrast, treatment plant-level benchmarking studies are much more prevalent (Fraquelli and Giandrone 2003; Molinos-Senante, Hernández-Sancho, and Sala-Garrido 2014; Molinos-Senante et al. 2016; Guerrini et al. 2016; Fuentes, Torregrosa-Martí, and Hernández-Sancho 2017; Castellet-Viciano, Torregrossa, and Hernández-Sancho 2018).

Guerrini et al. (2015) carried out a two-stage analysis using 62 observations of 44 wastewater utilities and 18 water and wastewater utilities. In the first stage, they calculated efficiency scores through data envelopment analysis, or DEA; in the second stage, they conducted a regression analysis of those efficiency scores obtained in the first stage. They found that Danish wastewater utilities achieved low average efficiency, which was significantly affected by operational and environmental variables such as firm size, the degree of investment diversification, and population density.

Blaeschke and Haug (2018) calculated efficiency scores using a conditional order-m metafrontier method. They especially focused on intermunicipal cooperation, and then applied three types of sewerage services (self provided, jointly provided, and contracted out). A sample of 193 observations was sourced for German municipal wastewater services located in the state of Hesse. The results suggest that municipalities that jointly provide wastewater services exhibit lower technical efficiency than municipalities that self-provide wastewater services or contract with other municipalities. Moreover, cooperation in wastewater services seems to generate scale effects that are beneficial mainly for small municipalities, and intermunicipal agreements or contracts are more efficient than intermunicipal bodies if cooperation is restricted to sewerage pipe cleaning.

Fraquelli and Giandrone (2003) modeled operating costs for 103 Italian WWTPs observed in 1996. They found that economies of scale existed for smaller plants and that they had substantially higher unit costs than larger plants. Further, their findings also suggested economies of scope from vertical integration between water distribution and sewage collection. The authors noted that their analysis was based exclusively on the operating costs of treatment; therefore, the capital and financial expenses should be further considered to provide a more accurate evaluation at the company level.

Hernández-Sancho, Molinos-Senante, and Sala-Garrido (2011) estimated cost functions of three different treatment processes: (i) suspension growth processes such as extended aeration without nutrient removal, activated sludge without nutrient removal and activated sludge with nutrient removal; (ii) attached growth processes such as bacterial beds, peat beds, and biodisk; and (iii) tertiary treatment, using 341 observed Spanish WWTPs. The results show that each technology exhibits economies of scale, but scale economies are smaller in attached growth processes than in suspended growth processes.

Molinos-Senante, Hernández-Sancho, and Sala-Garrido (2014) and Molinos-Senante et al. (2016) used a sample of WWTPs in the Valencia region on the Mediterranean coast of Spain, analyzing 192 and 175 observations, respectively, which include time series data from 2003 to 2008 . The 2014 study adopted an approach of non-radial data 
envelopment analysis and found that some external factors, such as plant size, capacity, age, and treatment technology, have influenced global and individual efficiency scores. Meanwhile, the 2016 study estimated a Malmquist-Luenberger productivity index, taking into account undesirable outputs such as greenhouse gas emissions and sewage sludge. The results obtained show that the omission of undesirable outputs led to an underestimation of productivity growth, and this had a significant effect in terms of the productivity index and its components.

Guerrini et al. (2016) calculated conditional order-m efficiency scores after controlling for several performance drivers categorized as wastewater features, plant technology, other plant features, output quality, and sludge disposal method. The sample was sourced from WWTPs of water utilities operating in the Tuscany region in Italy, and the number of observations was 137. The authors clarified that operational variables affected WWTP efficiency scores, so plant managers should monitor these operational variables constantly to improve performance.

Castellet-Viciano, Torregrossa, and Hernández-Sancho (2018) estimated three separate energy cost functions for 156 small, medium-sized, and large WWTPs in Valencia and provided evidence for relevant drivers of energy costs. The results suggest that energy costs are most sensitive toward mismatch of predicted and operational inflows for large WWTPs, which indicates that the cost modelling of these systems must take into account the changing environments that are crucial for capacity planning.

The pioneering benchmarking studies in Japan were all conducted at the level of the public sewerage system (PSS) operating company level and not at the sewage plant level. Thus, Nakayama (2001) estimated a translog cost function for a sample of relatively large city-owned sewerage utilities in the years 1991 to 1999. Extremely large cities such as Tokyo and Yokohama were excluded from the sample of 270 observations. The obtained results demonstrate that significant economies of density existed at the sample mean, but economies of scale did not exist. Further, the study also found that significant economies of scope exist between wastewater treatment and sludge treatment. Terada (2003) calculated efficiency scores with data envelopment analysis for PSSs operating only wastewater collection (not rainwater collection) with separate sewer pipes. The number of observations was 166 in 1997. The main result was that relatively large-scale utilities had high efficiency and small-scale utilities had low efficiency, but the range or efficiency scores was large. Kobayashi et al. (2004) adopted stochastic frontier analysis, or SFA, and estimated cost inefficiency as well as decomposing efficiency into technical, allocative, and price inefficiency for the whole PSS operation as well its subsystems. The sample was made up of 407 PSSs operating both wastewater collection and wastewater treatment. However, this study only confirmed the validity of the model and did not reach policy recommendations based on the measurement results of inefficiency.

However, these earlier Japanese studies should be updated for several reasons. First, none employed operating characteristics, sample composition controls, or modelling approaches that would control for the impact of PSS outsourcing of treatment activities to RBSs. Second, as was briefly discussed in the introduction and will be detailed further in the immediately following section, Japan differs from most countries because, within their boundaries, municipalities operate multiple sewage entities. Thus, modelling PSSs without accounting for the operation of non-PSS sewage entities within a municipality may result in a biased assessment of scale and scope economies as well as the estimated efficiency of sewerage services. 


\section{A BRIEF HISTORY AND THE STRUCTURE OF THE SEWERAGE SECTOR}

The Sewerage Act was enacted in 1900 to solve problems of flooding caused by rainwater and to prevent the occurrence of infectious diseases caused by sewage. It specified that sewerage utilities were to be owned and operated by municipal government, and the establishment of new sewerage utilities (i.e., PSSs) required approval by a competent minister. During the early decades of the 20th century, sewerage services were not widespread since other priorities involving water supply were seen to deliver improvements in hygiene, and there also were financial constraints. Therefore, many cities did not construct PSSs. In the 1930s, sewerage projects began in several cities to counteract unemployment. However, after the Second World War, improvements in water supply provision were again prioritized over improvements in sewage collection and treatment.

The revision of the Sewerage Act in 1958 supported urban development by facilitating the use of a combined sewerage system designed to collect rainwater and wastewater in the same pipe, with the aim of improving both urban environment and public health. However, the increasing pollution of rivers significantly impacted major cities across the country, requiring urgent government measures. Against this backdrop, the amendment of the Sewerage Act of 1970 added "To contribute to the preservation of water quality in public waters" to its purposes and completed the three basic principles of the current sewerage system of "prevention of flooding in urban areas," "improvement of public health," and "conservation of water quality in public water bodies." Furthermore, a comprehensive basinwide planning of the sewerage system was implemented at the same time, with prefectures being made responsible for these plans. Moreover, the 1979 Sewerage Act also legally enabled the establishment of RBS entities, which provide sewage treatment facilities serving at least two municipalities, while the collection and municipal self-treatment of sewage remained under the independent control of municipally owned PSSs. However, it must be noted that several RBS systems had already been established, with Osaka Prefecture being the earliest in 1964.

Community plants, which treat human waste and domestic wastewater collected by pipes, are another type of wastewater system that appeared in areas not served by PSSs in the 1960s to meet the needs for flush toilets due to the rapid expansion of residential suburban areas. These systems were installed in accordance with the general waste treatment plan established by municipalities and were required by the 1970 Waste Management and Public Cleansing Act. Community plant systems could be constructed at relatively low cost and in a short period of time.

In 1967, the Basic Pollution Control Law was enacted and environmental standards were established. In 1970, the Water Pollution Control Law was amended to set wastewater standards for water pollution and to expand the legal responsibilities of PSSs and RBSs for the quality conservation of public water bodies. Furthermore, in 1978, the total quantity regulation system, which set standards for effluent released into public water bodies, was introduced, and the role of sewerage entities in water quality conservation became even more important. With this tightening of environmental regulations, the Japanese government also started to expand sewerage systems in rural areas in the 1970s, noting that PSSs and RBSs had been primarily focused on serving urban areas. ${ }^{3}$

3 Note that before 1971, special public sewerage systems (SPSs) had already been implemented by MLIT as an urban storm drainage system, mainly used for specific business activities such as factories, and 
Thus, in 1973, drainage facilities for agricultural communities (DAG) were enabled as part of the Farming Village Improvement Model Project (Nouson Sogo Seibi Model Jigyo) promoted by Ministry of Agriculture, Forestry and Fisheries (MAFF). By definition, a DAG could be installed only in agricultural promotion areas where it was necessary to promote agriculture according to the Agriculture Promotion Area Improvement Plan determined by municipalities. The size of a DAG was defined as the population served of about 1,000 or less, and the number of connected households was required to be more than 20 .

In 1975, specified environmental preservation public sewerage systems (SEPSs) were enabled by the Sewerage Act to protect the environment such as those in rural areas and natural parks. The population served of SEPSs was required to be less than 10,000 . In 1978 and 1980, respectively, drainage facilities for fishery communities (DFSs) and drainage facilities for forestry communities (DFRs) were established under MAFF regulations to protect the environment of fishing and mountain villages, and the population served size of each entity was required to be between 100 and 5,000 for DFSs and about 1,000 or less for DFRs. As a result, the current complex legal and regulatory framework allowing for a significant number of different types of sewerage entities to operate in any given municipality was completed by $1980 .{ }^{4}$

Figure 2 illustrates the trend in the total number of sewage entities in Japan from 1999 when data become readily available. From 1999 to 2003, the total number of entities expanded rapidly, as municipalities continued to establish new entities serving the communities targeted by the government policy initiatives just discussed. However, this steady increase was transformed into a dramatic decrease in the number of sewerage entities between 2003 and 2005 because of the Great Heisei Era Consolidation of municipalities. Nevertheless, the municipal consolidation reduced the number of entities primarily via the simple merger of entities of a given type within the new municipal boundaries, and not via the relatively limited number of mergers between larger PSS entities and other entity types. Moreover, after the impact of a few relatively late municipal mergers that occurred after 2005, the total number of entities stabilized around 2009. Thus, a total of 3,639 sewerage entities existed in 2016; on average, there were more than two non-RBS sewerage entities for each of Japan's municipalities, thereby clearly illustrating the proliferation of different sewerage entity types in Japan

had their own associated treatment plant. However, such systems are not particularly prevalent and only 10 such systems exist in Japan today.

4 As environmental issues such as energy-saving, recycling, and safe drinking water became more relevant in the 1990s, the Basic Environmental Law was enacted in 1993 in order to secure greater purity and safer drinking water, and several laws aimed at the conservation of water quality were enacted one after another in 1994, thereby positioning improved sewerage systems as the center of domestic wastewater measures. Moreover, the Sewerage Law was revised yet again in 1996 and stipulated an obligation to reduce the amount of generated sludge being landfilled by promoting alternative uses such as for building materials. 
Figure 2: Trend in the Number of Sewerage Systems

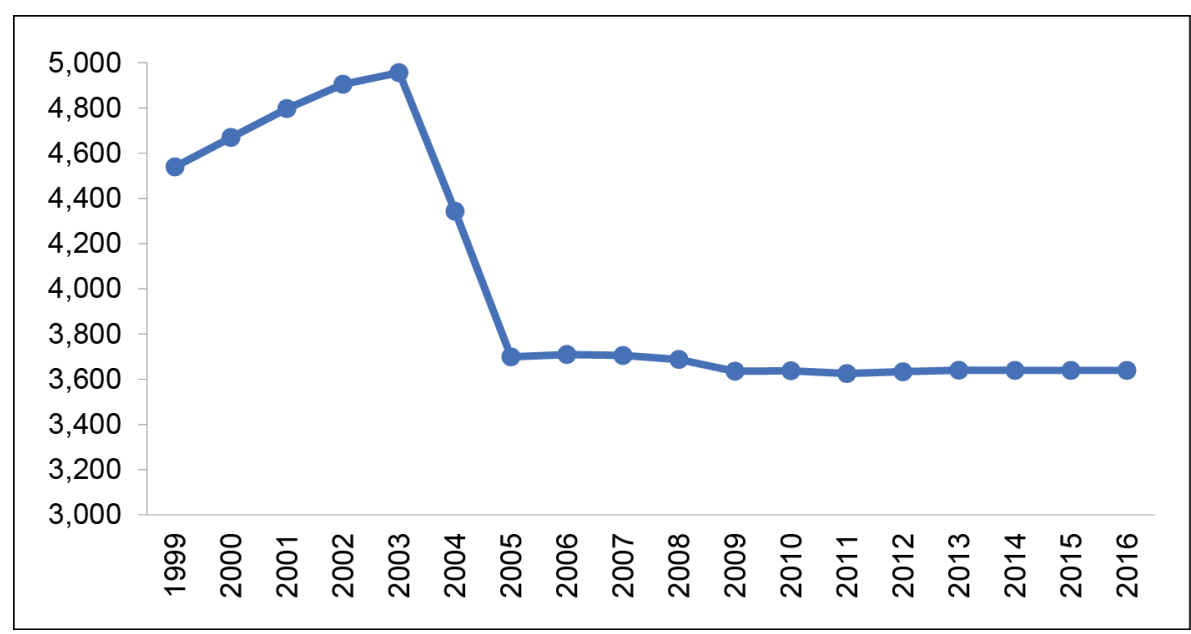

Source: Annual Local Public Enterprises Statistics (ALPES) database.

Table 1 further details the distribution of Japanese sewerage entities with respect to their ownership and the population served of the municipality in FY2016, using data available from the Annual Local Public Enterprises Statistics (ALPES) database. ${ }^{5}$ From this table, it is evident that RBSs are mainly under the control of and operated by prefectures, whereas almost all other sewerage entities are operated and controlled by municipalities. Thus, only 23 sewage entities are cooperatives, which are operating entities that are jointly owned by multiple municipalities. The 1,189 PSSs are clearly the largest entities and account for $92.86 \%$ of the entire served population, but over half the PSSs provide services in cities with less than 30,000 people. In contrast, the moderately sized (by Japanese standards) SEPS and DAG entities, respectively, only account for $3.68 \%$ and $3.29 \%$ of the population served and make up $20.67 \%$ and $25.06 \%$ of all sewage entities. The remaining 740 entities account for only $0.17 \%$ of the population served and $20.34 \%$ of all Japanese sewerage entities. Table 1 thus supports the inescapable conclusion that Japan's predominantly municipally controlled but multiple-entity system of sewerage industry organizations has resulted in a highly fragmented industry structure.

In addition to operating with this highly fragmented industry structure, at the onset of the 21st century, Japan also faced major social structural change, as its population peaked in 2008 and began to decline. Especially in rural municipalities, the population had already begun to decline before 2008 , and subsequently sewerage revenues have been decreasing, which will create a funding crisis for the sector in the near future. In 2005, MLIT formulated its Sewerage Vision 2100 (Gesuido Vision 2100) to achieve a 21st century sewerage system to support the sustainable development of regional communities. However, as the implications of population decline and aging population, the severity of frequent natural disasters, and the investment needs associated with aging facilities had become more serious, this vision needed to be revised, and MLIT formulated the New Sewerage Vision (Shin Gesuido Vision) in 2014. The resulting 2015

5 Data on the PSS, RBS, and SPS entities regulated by MLIT; DAG, DFS, DFR, and simplified drainage system entities regulated by MAFF; and small-scale combined wastewater treatment and individual Johkasou facilities serving fewer than 20 households regulated by the Ministry of Internal Affairs and Communications (MIC) are included in ALPES. However, MOE regulated municipally installed Johkasou systems serving 20 or more households, individually installed and maintained Johkasou systems, and community wastewater treatment plants providing sewerage systems for multiple-dwelling complexes are not included in the ALPES data. 
revisions of the Sewerage Act required municipalities to inspect sewer pipelines for corrosion at least every 5 years, improve their maintenance, and develop medium-term plans.

Table 1: Number of Sewerage Entities with respect to Entity Type and Size (FY2016)

\begin{tabular}{lrrrrrrr}
\hline & RBS & PSS & SEPS & DAG & $\begin{array}{r}\text { SPS, DFS, } \\
\text { and DFR }\end{array}$ & Other & Total \\
\hline Prefecture & 42 & 1 & 2 & 0 & 3 & 0 & 48 \\
Government ordinance city & 0 & 20 & 11 & 12 & 2 & 5 & 50 \\
$>300$ & 1 & 35 & 0 & 0 & 0 & 0 & 36 \\
$100-300$ & 0 & 132 & 0 & 0 & 0 & 0 & 132 \\
$50-100$ & 0 & 158 & 1 & 0 & 0 & 0 & 159 \\
$30-50$ & 0 & 123 & 10 & 2 & 0 & 2 & 137 \\
$10-30$ & 0 & 352 & 76 & 70 & 0 & 2 & 500 \\
$<10$ & 0 & 339 & 619 & 815 & 200 & 524 & 2,497 \\
Cooperative & 3 & 14 & 5 & 0 & 0 & 1 & 23 \\
Drainage only & 0 & 5 & 1 & 1 & 0 & 0 & 7 \\
Under construction & 0 & 10 & 27 & 12 & 1 & 0 & 50 \\
\hline Total entities & 46 & 1,189 & 752 & 912 & 206 & 534 & 3,639 \\
\% of all entities & 1.26 & 32.67 & 20.67 & 25.06 & 5.66 & 14.67 & 100.00 \\
\hline Total population served & - & 95,988 & 3,806 & 3,400 & 169 & 8 & 103,371 \\
\% of population served & N/A & 92.86 & 3.68 & 3.29 & 0.16 & 0.008 & 100.00 \\
\hline
\end{tabular}

DAG = drainage facility for agricultural communities, DFR = drainage facility for forestry communities, DFS = drainage facility for fishery communities, N/A = not available, PSS = public sewerage system, RBS = river basin system, SEPS = specified environmental preservation public sewerage system, SPS = special public sewerage system.

Notes: Population served is shown in thousands. Other entities include simplified drainage systems, and small-scale municipally operated combined wastewater treatment facilities and Johkasou systems serving 20 or fewer households.

MLIT policy makers have since begun to focus more on improving the cost-effectiveness of sewerage services, with WAC as one of the most important approaches under consideration and development. The next section therefore focuses on these current policy developments.

\section{DIRECTION OF THE GOVERNMENT'S POLICY REFORM}

MLIT recognized the progress made under a severe business environment accompanied by a declining population, a lack of management skills, and aging facilities, among other challenges. Based on such social changes, the ministry established the New Sewerage Vision Acceleration Strategy Review Committee in 2017 and formulated the New Sewerage Vision Acceleration Strategy (Shin Gesuidou Vision Kasoku Senryaku). Six policy themes were selected to be implemented immediately: (i) promotion of publicprivate partnership; (ii) improvement of added value by utilizing sewer; (iii) optimization of wastewater treatment systems; (iv) establishment of management cycles; (v) promotion of water infrastructure exports; and (vi) promotion of disaster prevention and reduction. Furthermore, from the viewpoint of smooth promotion of each measure, Two further policy themes were chosen that would nurture the sewerage industry so that it can cope with the change in social situations and also disseminate information toward 
public understanding: (vii) fostering of a sewerage industry that meets public needs; and (viii) dissemination to the public. MLIT will review these policies annually.

Most significantly, given our focus on WAC, the Japanese government in a 2017 policy document on economic and fiscal management and reform stipulated set goals for promoting regionalization by FY2022 in order to ensure the sustainable management of water supply and sewerage. In response, MLIT held a meeting of its Subcommittee on Wide-Area Cooperation and Sharing of Facilities (Koikika Kyodoka Kento Bunkakai) in 2018, jointly with MIC, MAFF, and MOE. And, in order to facilitate the planning of WAC and facilities sharing plan, MLIT decided to organize and develop case examples as a model plan. Five prefectures were selected (Akita, Iwate, Shizuoka, Shimane, and Kumamoto), with each prefecture divided into several "subprefecture" regions. ${ }^{6}$ Each of the five prefectures chose a subprefecture and considered specific measures that could be put in place for WAC and sharing of facilities. The discussions were summarized in an interim report titled Manual for Formulating Plans for Wide Area Cooperation and Sharing Facilities (Koikika Kyodoka Keikaku Sakutei Manual). However, this preliminary work lacked sufficient detail, and further detailed examples of WAC and sharing of facilities were examined in the following year.

In 2019, the second year of the subcommittee, MLIT focused on two things to discuss regarding WAC and sharing of facilities: size and leadership. The subcommittee reasoned that the size of a cooperation area should be as large as a governmentdesignated city or of a core city, ${ }^{7}$ and that it is important for the business entity to have the technical capacity to formulate an optimal plan for the sewerage business as well as the ability to take leadership and obtain the consensus of the stakeholders. Three prefectures were selected based on these points: Nagano, Okayama, and Nagasaki. In order to facilitate WAC and sharing of facilities, Nagano is utilizing the Nagano Prefecture Sewerage Corporation which is owned by the prefecture and its municipalities; Okayama is utilizing the Japan Sewage Works Agency, which is providing technical support in the form of sewerage facility construction, research and development of the sewerage business, training of sewerage engineers, and so on; and Nagasaki is utilizing Nagasaki City, which is the core city of the prefecture. A revised version of the 2019 interim report was compiled in April 2020.

As we have seen, MLIT has been investigating WAC cases in multiple prefectures and developing an understanding of how to apply it in other prefectures. However, these examples have been simple surveys of specific cases in some municipalities, and important factors influencing the operating environment such as population density, geographic and/or topographic conditions, and others have not been considered in sufficient detail. Moreover, we believe that further factors attributable to the organization of Japan's sewerage industry such as size fragmentation, entity type fragmentation, and organizational fragmentation must therefore be considered. Doing so will allow a better understanding of the current operating environment and the resulting approach to WAC that will need to be taken in different areas. We therefore conduct a case study focusing on Hyogo Prefecture.

6 MLIT called these subprefecture "blocks" but, as not all prefectures agree with this term, we will use the term "subprefecture."

7 A government-designated city is defined by government ordinance as having a population of 500,000 or more; a core city is defined by government ordinance as having a population of 200,000 or more, but an application from the municipality is required. 


\section{CASE STUDY: HYOGO PREFECTURE}

\subsection{Hyogo Prefecture}

Hyogo Prefecture is located in Japan's Kansai region, which includes multiple prefectures and large cities, including Kobe, Osaka, and Kyoto. The largest city in Hyogo Prefecture is Kobe, which is part of the highly urbanized densely populated part of the prefecture situated along Osaka Bay, and which continues to the eastern end of Hyogo Prefecture (Amagasaki) and as far west as Himeji. Nevertheless, Kobe also includes a large rural agricultural hinterland situated north of Mount Rokko. Thus, as is often the case in Japan, mountainous terrain has prevented the northward spread of Kobe's urban development and has resulted in a sharp geographically determined dichotomy in the city's land use and settlement patterns.

The choice of Hyogo Prefecture for our case study is justified by our conclusion that the prefecture reflects much of the geographic and demographic variation found across the country but within a single prefecture. Japan consists of four main mountainous, relatively narrow islands, with long terrain oriented north to south. The temperature difference between the north and south is large: the average annual temperatures from 1981 to 2010 were $8.9^{\circ} \mathrm{C}$ in Sapporo, Hokkaido; $18.6^{\circ} \mathrm{C}$ in Kagoshima, Kyushu, the southernmost city of the four main islands; and $23.1^{\circ} \mathrm{C}$ in Naha, Okinawa (Japan Meteorological Agency). Furthermore, the climate is very different between the east and west coasts, especially in winter, when the Sea of Japan side is colder and very snowy, while the Pacific Ocean side is warmer with little snow. Hyogo Prefecture is therefore ideal for a case study, because it is the only prefecture facing both the Sea of Japan and the opposite Seto Inland Sea on its Pacific Ocean side. Thus, as with much of Japan, Hyogo Prefecture has a large rural hinterland in the north and more urbanized areas in the south. Furthermore, the prefecture is representative of another characteristic of the country's mountainous terrain in that it is largely forested: Thus, the forest rate in Japan is $67 \%$, which is the same for Hyogo Prefecture (Forestry Agency).

Figure 3 provides a functional and organizational map of the sewerage systems in Hyogo Prefecture (excluding Awaji Island, which is also part of the prefecture) as provided by the Hyogo Prefectural Land Maintenance Department. The color coding indicates the type of sewerage entity responsible for sewage treatment. In the yellow, light purple, and dark purple areas, PSSs are responsible for wastewater collection. However, in the yellow areas, PSSs are also responsible for sewage treatment, and in the light purple and dark purple areas, wastewater collected by PSSs is treated in large sewage treatment plants operated by Hyogo Prefecture's RBS authority. Though relatively difficult to discern in the map, DAG-served areas are indicated in light green and DFSserved areas are indicated in dark green. Finally, dark brown areas are served by community plants, which reach only $1.1 \%$ of the prefecture's population and are under the jurisdiction of MOE. The community plant systems do not report data in the ALPES database and are therefore necessarily excluded from the analysis for this study. In contrast, while $6.3 \%$ of the prefecture's population is served by SEPSs, they are not identified in Figure 2, but are included in this study.

Figure 3 further reveals the six river basin systems served by the six wastewater treatment plants operated by Hyogo Prefecture's RBS Authority: Inagawa RBS, Mukogawa Upstream RBS, Mukogawa Downstream RBS, Kakogawa Upstream RBS, Kakogawa Downstream RBS, and Ibogawa RBS. All of these RBS-dependent sewage treatment systems operate in or near the prefecture's highly urbanized southern area. Nevertheless, there is a distinction between the RBS systems (such as Ibogawa and Kakogawa Upstream) that collect sewage from lower-density areas and deliver to 
relatively smaller RBS plants and other RBS plants that serve more densely populated areas. In contrast, DAG-served areas are more widespread in the more rural northern and western areas of Hyogo Prefecture (as are SEPS-served areas, which are not indicted on the map), while the white areas are unserved. Nevertheless, given the proliferation of sewerage entity types discussed earlier, it should be noted from Figure 3 that PSSs serve all areas of the prefecture, but that PSS treatment areas in the hinterland are small and geographically fragmented and largely do not have access to RBS treatment plants. Moreover, the single largest area served by a DAG is in Kobe's rural hinterland, given that mountains separate it from the otherwise densely populated south of Hyogo Prefecture.

\section{Figure 3: Sewerage Systems in Hyogo Prefecture}

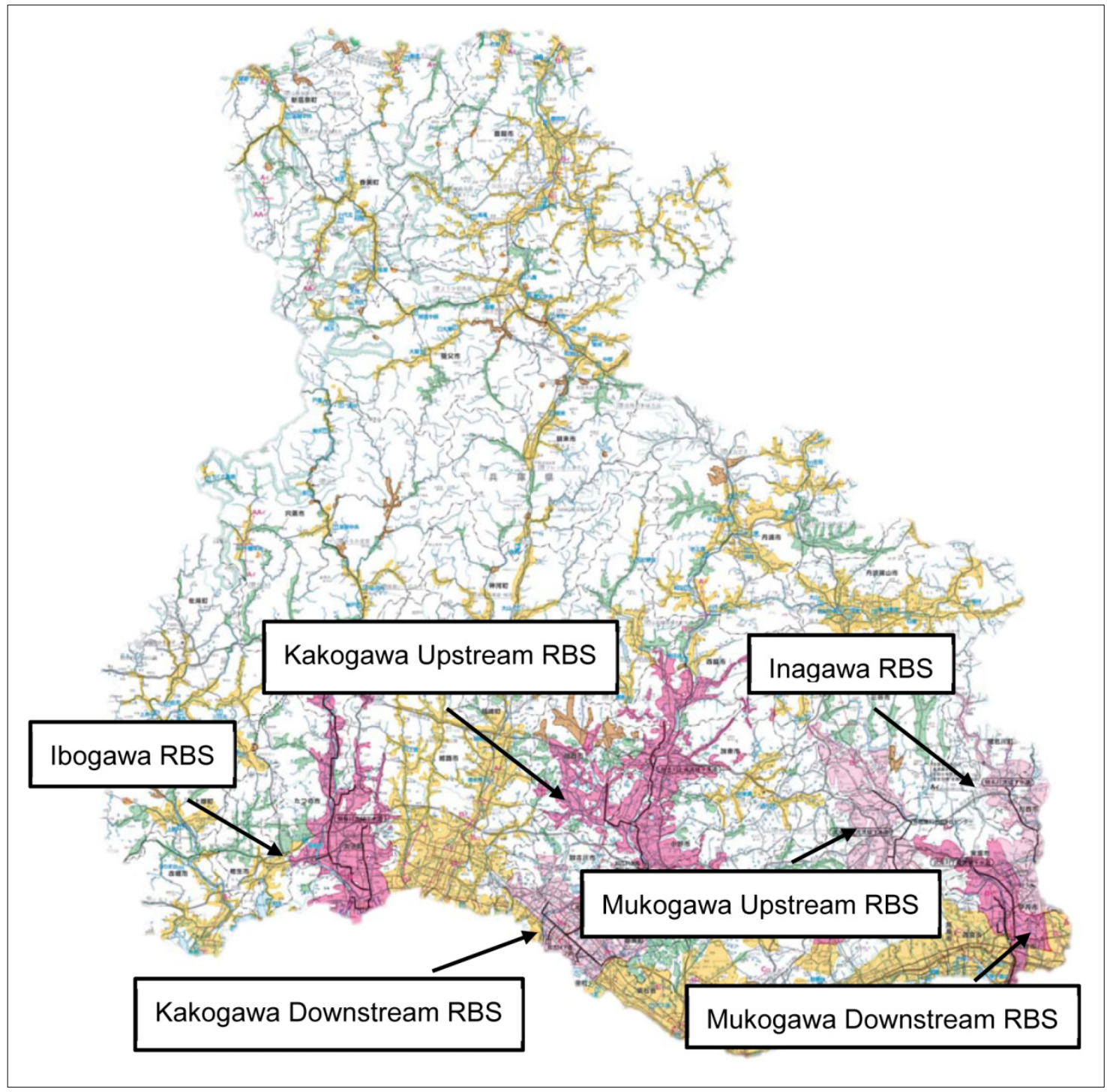

RBS = river basin system

Source: Modified by authors based on Hyogo Prefectural Land Maintenance Department. 
Turning to Figure 4, we first consider the municipal organization of Hyogo Prefecture, including the impact of the Great Heisei Era Consolidation. Thus, the map on the left of the figure details the prefecture's municipal boundaries in FY2004, with the color coding further indicating the boundaries of the 10 subprefectures: Tajima, Tamba, West Harima, Central Harima, North Harima, East Harima, Hanshin North, Hanshin South, Kobe, and Awaji. However, these historically defined subprefectures currently have no independent government or political authority, although each has a Hyogo Prefecture branch office set up to support prefecture administration.

Figure 4: Municipality Merger and Population Density of Hyogo Prefecture (people per square kilometer)

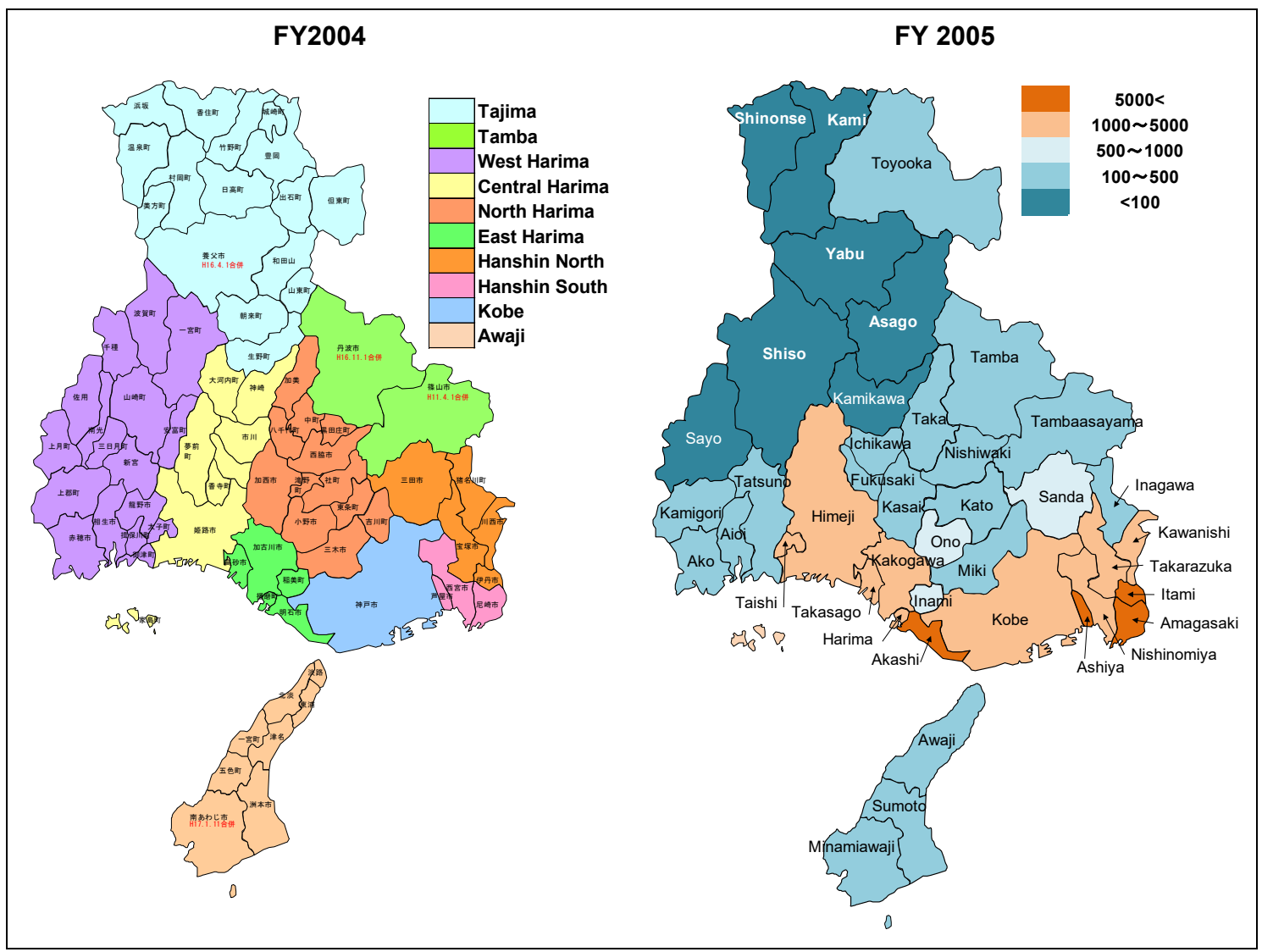

$\mathrm{FY}=$ fiscal year.

Source: Modified by the authors based on Regional Policy Statistics Study Group.

As the Cabinet Office of Japan actually began promoting municipal mergers in 1999, the map on the left already reflects substantial municipal consolidation. In the case of Hyogo Prefecture, there were 91 municipalities (21 cities and 70 towns) before 1999 and 18 towns merged into 4 cities by the end of FY2004, reducing the number of municipalities to 77 (25 cities and 52 towns, as shown in Figure 4). However, further substantial municipal consolidation took place in FY2005, reducing the number of municipalities to the current 41 ( 29 cities and 12 towns, as indicated on the map on the right of Figure 4). ${ }^{8}$ In addition to detailing the current boundaries of the municipalities, the color coding of the map on the right also reveals their administrative population

8 As the WAC consolidation policies that we will consider are based on these subprefectures, it is important to note that all municipal mergers occurred within the boundaries the 10 existing subprefectures. 
density. Thus, the map clearly reveals the difference between the densely populated municipalities in the south and the less densely populated municipalities in the north, the west, and the island of Awaji. While Kobe is the largest city in the prefecture and contains large, very densely populated districts, the presence of the hinterland in the north within its administrative boundary, as discussed earlier, means that its overall administrative population density is not in the highest municipal density category in Figure 4.

Further careful consideration of the two maps in Figure 4 reveals that the FY2005 municipal mergers were predominantly in rural areas. In the densely populated south, no mergers took place in Kobe, Hanshin North, Hanshin South, and East Harima subprefectures, while in Central Harima, the most significant merger was the consolidation of the densely populated Himeji with several of its smaller neighboring cities. In contrast, in areas of low density such as Tajima and West Harima subprefectures, the number of municipalities decreased from 15 and 16 to 5 and 7 , respectively.

Understanding the performance impact of these earlier mergers on the sewerage industry is part of our concurrent research agenda, However, this paper first considers the characteristics of the sewerage sector within Hyogo Prefecture's existing municipal structure in order to provide initial conclusions with regard to potential future WAC of the industry across the current municipal boundaries.

\subsection{Data and Methodology}

Our analysis is based on a cross-section of data for Hyogo Prefecture's municipally owned sewage entities observed in FY2016, which were the most recent data available when analysis began. Data were primarily drawn from the ALPES database provided by MIC, with further supplemental data drawn from the Statistics of Sewerage Works (SSW) database (Gesuidou Toukei) provided by the Japan Sewerage Works Association. The ALPES database provides operating entity-based data and includes both operational and financial data, while the SSW database contains sewage collection service area-based data as well as sewage plant-based data. However, as was discussed earlier, municipalities are the primary decision-makers in Japan's sewerage industry, and our analysis therefore focuses on municipal operating and cost characteristics, using data for all municipally owned entities aggregated to the municipal level. Moreover, this methodological decision requires us to primarily rely on the ALPES database, because it provides data for the overwhelming majority of served customers observed in Hyogo Prefecture. In contrast, the SSW database excludes data on DAG, DFS, and DFR entities, which between them account for 328 of the 374 municipally owned sewage treatment works identified in the ALPES data. Thus, even though data on PSS and SEPS entities that are available in the SSW database would cover the vast majority of the served population, relying on these data alone would preclude appropriate analysis of municipal operating characteristic, particularly in more rural areas of the prefecture.

Given this discussion of the underlying data, our analysis considers the sewerage system operating characteristics of Hyogo Prefecture's 41 municipalities (29 cities and 12 towns) as well as its 10 historic subprefectures. Moreover, it should be emphasized that this approach relates closely to MLIT's promotion of WAC, as Hyogo Prefecture put forward a preliminary suggestion to MLIT that it could pursue WAC of sewerage activities within regions that are consistent with its subprefecture boundaries. The prefecture proposed eight tentative WAC regions, which are identical to the subprefectures identified in the map on the left of Figure 4. The ninth proposed WAC region also respects the existing subprefecture boundaries but includes both Kobe and Hanshin South subprefectures. 
We therefore proceed by considering the operating characteristics of the nine potential WAC regions identified by Hyogo Prefecture, as well as those of each municipality.

\subsection{Characterizing the Proposed Wide-Area Consolidation Regions}

Table 2 provides aggregate operating characteristics for Hyogo Prefecture's proposed WAC regions, and categorizes the nine potential WAC regions as fully decentralized (FDWAC), intermediately centralized (IDWAC), or more centralized (MCWAC). The rationale for this typology is now discussed with reference to the table.

Tajima, Tamba, and Awaji subprefectures are classified as FDWACs, because low population density, low urban population shares, and relatively small settlement sizes have resulted in a reliance on a large number of relatively small sewage treatment systems that require relatively long lengths of mains per population served. Moreover, in the FDWAC regions, municipal entities have no access to RBS treatment plants and therefore treat $100 \%$ of the sewage they collect. The rural fragmented population settlement patterns in these regions are further demonstrated by the fact that, when taken together, their population served coverage ratio is only $76 \%$. Moreover, PSS entities only serve $38 \%$ of the population served in FDWACs, and other entity types that generally serve more rural areas therefore account for the vast majority of sewerage provision. However, even PSS sewage treatment plants in these areas are relatively small, with an average population served of 8,200 . Thus, the vast majority of FDWAC residents are served by very small, decentralized sewage treatment systems

West, North, and Central Harima are characterized as IDWACs. While these regions operate a relatively large number of sewage treatment plants and have population served densities only moderately higher than the FDWACs, they serve a substantially large share of their administrative area and classify more of their population as being settled in urban areas, and therefore require substantially less mains length per population served and provide services to $92 \%$ of their population. The IDWAC regions also differ significantly from the FDWACs, because they have at least partial access to RBS treatment plants. Thus, our estimates based on the SSW database suggest that $37 \%$ of all IDWAC treatment occurs in an RBS sewage treatment plant. Moreover, relative to the FDWACs, IDWAC PSS entities provide a substantially larger portion of FDWAC sewerage services, and account for $77.4 \%$ of all population served. Thus, while 216 nonPSS plants operate at an estimated average scale of only 600 people served, a substantial portion of IDWAC residents have their sewage treated in either centralized RBS treatment plants or in relatively larger PSS treatment plants with an average scale of 44,200 people served.

East Harima, Kobe and Hanshin South, and Hanshin North are characterized as MCWACs. These regions have relatively high population densities, are highly urbanized, and by Japanese standards provide sewerage services to a large share of their administrative areas. As a result, they require very low mains length to provide services to $99 \%$ of their population. Moreover, PSSs collect sewage from $98 \%$ of the population receiving sewerage service in MCWAC regions. Most fundamentally, these regions can rely on highly centralized large treatment plants to serve almost all their population. Thus, only 43 of the 62 municipally operated sewage plants in the MCWAC region serve DAG enclaves in the region, and in total non-PSS entities only serve 26,3000 MCWAC residents, with an estimated average non-PSS plant serving only 800 people. $^{9}$ In contrast, for the remaining 3.967 million people whose sewage is

9 Kobe's DAG, discussed earlier, accounted for 25 of these DAG plants. 
collected by PSSs or SEPSs in the MCWAC regions, it is treated in either the 19 PSSoperated plants in this region, which have an average population served of 125,700 or in RBS treatment plants. Thus, the MCWAC regions can be characterized as benefiting from both significant scale economies in sewage treatment and low mains length per customer resulting from large, centralized sewerage systems.

Table 2: Operating Characteristics of Hyogo Prefecture's Proposed Wide-Area Consolidation Regions by Centralization Category

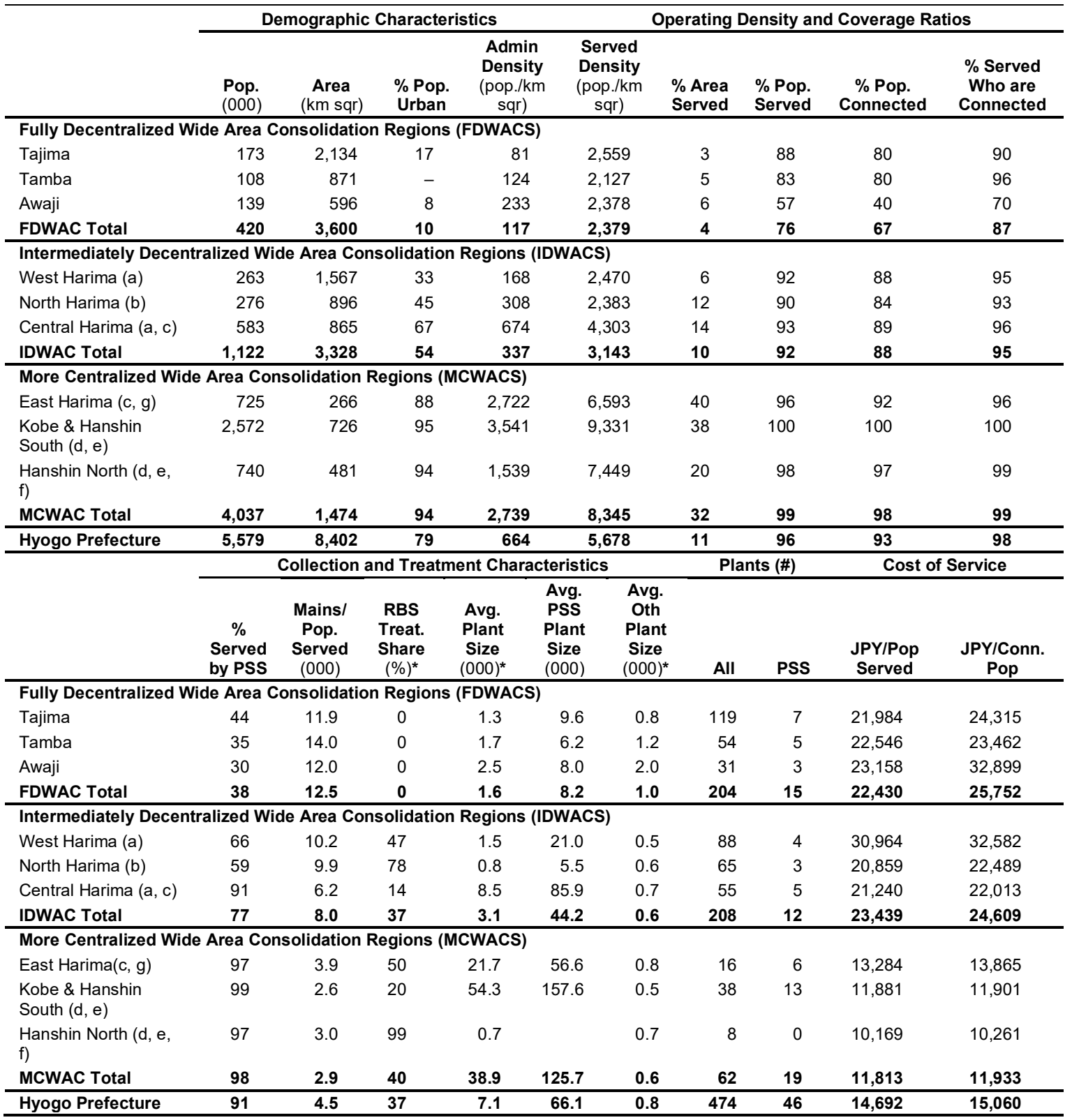

External Treatment by (a) Ibogawa RBS, (b) Kakogawa Upstream RBS. (c) Kakogawa Downstream RBS, (d) Mukogawa Downstream RBS, (e) Mukogawa Upstream RBS, (f) Inagawa RBS, (g) Himeji PSS.

* As data on external treatment is only available for PSS and SEPS's in the SWS database we have calculated these numbers assuming that all other entities always self treat.

PSS = public sewerage system, RBS = river basin system, SEPS = specified environmental preservation public sewerage system, SSW = Statistics of Sewerage Works.

In order to provide a better understanding of the implications of alternative approaches to measuring the provision of sewerage services in Japan, Table 2 also provides 
two further alternative coverage ratios to the population served measure we have discussed so far. We do this to draw an important distinction between the common definition of population served used in the Japanese system and an alternative-and we believe-more appropriate definition. The Japanese sewerage industry standard is to define population served as the population who have the potential to connect to a sewage collection system, regardless of whether they have chosen to connect to the system. The logic from a policy perspective may derive from the considerable effort in recent decades to expand sewerage service provision and resulting government encouragement and subsidy to expand sewerage networks.

A more standard measure for population coverage is consistent with available data on the number of people who have connected and therefore actually benefit from the ability to flush their waste directly into the sewerage system. Using this more standard measure reveals that coverage ratios in the FDWAC, IDWAC, and MCWAC regions respectively drop from $76 \%, 92 \%$, and $99 \%$ to $67 \%, 88 \%$, and $98 \%$, thereby strengthening the conclusion that in less centralized regions where non-sewered solutions are more cost-effective, the uptake of sewerage services is lower.

The final coverage ratio provided in Table 2 is the ratio of connected to population served, which is properly interpreted as a utilization ratio for installed sewerage systems. As this measure is only $87 \%$ in the FDWAC areas and $95 \%$ in IDWAC areas, it suggests that as decentralization increases, underutilization of installed sewerage systems increases. This suggests that while Hyogo Prefecture's more rural municipalities may be making costly investments to expand capacity, their citizens to a considerable extent are choosing not to take advantage of these costly investments.

Given these considerations, Table 2 finally provides two measures of costs per population served, using a standard Japanese government-defined measure of costs including maintenance costs and capital costs, as defined in the ALPES database, and alternatively transformed into an average cost of service using either population served or population connected. Two significant conclusions can be drawn from these cost of service measures. First, using the measure based on population connected reveals the cost benefits derived from the substantially more centralized sewerage systems in the MCWAC areas. Thus, the $¥ 11,933$ cost per population connected observed for the MCWAC areas is less than half the $¥ 25,752$ and $¥ 24,609$ cost per population connected observed in the FDWAC and IDWAC regions, respectively. ${ }^{10}$ Second, the considerable cost implications of providing underutilized sewerage systems in less centralized regions are revealed, as the cost of service ratio is respectively $14.8 \%, 5.0 \%$, and $1.0 \%$ higher in the FDWAC, IDWAC, and MCWAC regions, respectively, when calculated based on actual connected population rather than using the ALPES definition of population served. The size of this difference is significant enough to suggest that changing policies to encourage and/or mandate connection to existing sewage systems and/or reducing investment in underutilized sewerage systems could result in considerable improvements in the cost-effectiveness of decentralized sewerage systems in Hyogo Prefecture.

10 The relatively high unit costs for West Harima and North Harima can be partial explained by their reliance on the Ibogawa and Kakogawa Upstream RBS plants, which are the smallest RBS plants in Hyogo Prefecture and charge the highest unit cost for sewage treatment to municipalities. 
However, even if all such underutilization were eliminated, the MCWACs would still have substantial cost advantages derived from their more centralized sewerage systems that would be impossible to obtain in the more decentralized regions. Moreover, as such underutilization only moderately impacts the cost of service in the IDWACs, we now turn to a more detailed consideration of the FDWAC, IDWAC, and MCWAC regions so as to more carefully identify the characteristics of their municipalities, and thereby the outcomes that strategies will need to achieve if WAC is to successfully improve sewerage system performance in Hyogo Prefecture. These details are provided in Tables 3-5, which present the same statistics as shown in Table 2, but at the municipal level.

\subsection{Identifying Objectives for the Proposed WAC Regions}

Table 3 provides the municipal-level detail for 10 municipalities in the subprefectures of Tajima, Tamba, and Awaji that we have classified as FDWAC. As expected, the characterization we made at the subprefecture level in Table 2 follows through to the municipal level. Thus, none of these towns employ external RBS treatment. While several municipalities operate PSS treatment plants with an average population served in excess of 10,000 , most towns rely on PSSs for less than $50 \%$ of their collection, operate collection networks that require over 10 kilometers of mains per 1,000 people served, and rely disproportionally on a large number of small sewage treatment plants. These towns serve what are generally small, fragmented settlements, which are widely separated given that almost all towns provide sewerage networks to less than $5 \%$ of their area. Moreover, the fragmented nature of settlement, and hence sewage treatment systems, suggests that there is little potential for physical integration of sewerage systems in and across the FDWAC municipalities. Nevertheless, the municipal statistics reveal some important differences. Within Tajima subprefecture, Kami and Shinonsen have particularly low system utilization, compared to the subprefecture estimate, and in Awaji, there is less variation from the subprefecture-level estimate for this measure. Moreover, Awaji has particularly low system utilization, relative to the other FDWAC regions.

Focusing on the bottom of Table 3 reveals that the average FDWAC municipal and subprefecture populations are only 42,000 and 140,000, respectively, thereby suggesting that the small scale of municipalities in this region can potentially make it difficult to achieve efficiencies in the operation and management of sewerage services for which specialized labor, technical experience, and equipment are required. As summarized in Table 6, our analysis therefore leads us to characterize all 10 FDWAC municipalities as "rural - fragmented self-treaters" and to suggest that the primary objective of WAC of the prospective Tajima, Tamba, and Awaji subprefecture public sewer authorities (PSA) should be consolidation to improve operational performance without physical integration. We envision that this could be achieved by consolidation of operational management and contracting, thereby facilitating the achievement of scale via sharing of resources and maintenance depots. As no FDWAC municipality (with the possible exception of Toyooka) is significantly larger than other municipalities in the subprefecture, no obvious entities exist to lead WAC in the FDWAC regions. This suggests the need for the creation of new PSAs for each subprefecture that could operate cooperatives jointly owned by their municipality members, thereby allowing potential benefits from consolidation while ultimately retaining a degree of municipal control. Alternatively, each subprefecture's PSA could be operated by prefecturecontrolled entities, similar to the ownership form of most RBS authorities in Japan. However, this latter approach would require a potential transfer of both operational and political control and ownership from the municipal level to the prefecture level. 
Table 3: Operating Characteristics of Fully Decentralized Wide-Area Consolidation Regions Proposed by the Hyogo Prefecture Government (FDWACs)

\begin{tabular}{|c|c|c|c|c|c|c|c|c|c|c|}
\hline & \multicolumn{4}{|c|}{ Demographic Characteristics } & \multicolumn{6}{|c|}{ Operating Density and Coverage Ratios } \\
\hline & $\begin{array}{l}\text { Pop. } \\
(000)\end{array}$ & $\begin{array}{c}\text { Area } \\
(\mathrm{km} \mathrm{sqr})\end{array}$ & $\begin{array}{l}\text { \% Pop. } \\
\text { Urban }\end{array}$ & $\begin{array}{c}\text { Admin } \\
\text { Density } \\
\text { (pop./km } \\
\text { sqr) }\end{array}$ & & $\begin{array}{l}\text { Served } \\
\text { Density } \\
\text { (pop./km } \\
\text { sqr) }\end{array}$ & $\begin{array}{l}\% \text { Area } \\
\text { Served }\end{array}$ & $\begin{array}{l}\% \text { Pop. } \\
\text { Served }\end{array}$ & $\begin{array}{c}\text { \% Pop. } \\
\text { Connected }\end{array}$ & $\begin{array}{l}\% \text { Served } \\
\text { Who are } \\
\text { Connected }\end{array}$ \\
\hline Asago & 31 & 403 & - & 78 & & 2,428 & 2 & 67 & 63 & 95 \\
\hline Kami & 18 & 369 & - & 50 & & 2,526 & 2 & 91 & 67 & 74 \\
\hline Yabu & 25 & 423 & - & 58 & & 2,203 & 2 & 85 & 81 & 95 \\
\hline Tajima & 173 & 2,134 & 17 & 81 & & 2,559 & 3 & 88 & 80 & 90 \\
\hline Tamba & 42 & 378 & - & 112 & & 2,145 & 5 & 87 & 82 & 94 \\
\hline Tambasasayama & 66 & 493 & - & 133 & & 2,114 & 5 & 81 & 78 & 97 \\
\hline Tamba & 108 & 871 & - & 124 & & 2,127 & 5 & 83 & 80 & 96 \\
\hline Awaji & 139 & 596 & 8 & 233 & & 2,378 & 6 & 57 & 40 & 70 \\
\hline \multicolumn{11}{|c|}{ Average Characteristics Within Fully Decentralized Wide Area Consolidation Regions } \\
\hline WAC Region Avg & 140 & 1,200 & 8 & 146 & & 2,354 & 4 & 76 & 66 & 86 \\
\hline \multirow[t]{3}{*}{ Municipal Avg } & 42 & 360 & 9 & 132 & & 2,505 & 4 & 76 & 65 & 85 \\
\hline & \multicolumn{6}{|c|}{ Collection and Treatment Characteristics } & \multicolumn{2}{|c|}{ Plants (\#) } & \multicolumn{2}{|c|}{ Cost of Service } \\
\hline & $\begin{array}{c}\% \\
\text { Served } \\
\text { by PSS }\end{array}$ & $\begin{array}{l}\text { Mains/ } \\
\text { Pop. } \\
\text { Served } \\
(000)\end{array}$ & $\begin{array}{c}\text { RBS } \\
\text { Treat. } \\
\text { Share } \\
(\%)^{*}\end{array}$ & $\begin{array}{l}\text { Avg. } \\
\text { Plant } \\
\text { Size } \\
(000)^{*}\end{array}$ & $\begin{array}{c}\text { Avg. } \\
\text { PSS } \\
\text { Plant } \\
\text { Size } \\
(000) \\
\end{array}$ & $\begin{array}{c}\text { Avg. } \\
\text { Oth } \\
\text { Plant } \\
\text { Size } \\
(000)^{\star}\end{array}$ & All & PSS & $\begin{array}{l}\text { JPY/Pop } \\
\text { Served }\end{array}$ & $\begin{array}{l}\text { JPY/Conn. } \\
\text { Pop }\end{array}$ \\
\hline Tambasasayama & 20 & 13.1 & 0 & 1.8 & 3.6 & 1.6 & 30 & 3 & 21,406 & 21,974 \\
\hline Tamba & 35 & 14.0 & 0 & 1.7 & 6.2 & 1.2 & 54 & 5 & 22,546 & 23,460 \\
\hline Awaji & 48 & 12.5 & 0 & 5.6 & 6.7 & 4.9 & 5 & 2 & 26,362 & 36,463 \\
\hline Minamiawaji & - & 13.1 & 0 & 1.6 & & 1.6 & 24 & 0 & 23,063 & 34,461 \\
\hline Sumoto & 88 & 7.2 & 0 & 5.9 & 10.4 & 1.4 & 2 & 1 & 15,899 & 20,585 \\
\hline Awaji & 30 & 12.0 & 0 & 2.5 & 8.0 & 2.0 & 31 & 3 & 23,158 & 32,895 \\
\hline \multicolumn{11}{|c|}{ Average Characteristics Within Fully Decentralized Wide Area Consolidation Regions } \\
\hline WAC Region Avg & 36 & 12.6 & 0 & 1.8 & 7.9 & 1.3 & 68 & 5 & 22,563 & 26,890 \\
\hline Municipal Avg & 39 & 12.1 & 0 & 2.2 & 7.5 & 1.4 & 20 & 2 & 21,374 & 25,704 \\
\hline
\end{tabular}

* As data on external treatment is only available for PSS and SEPS's in the SWS database we have calculated these numbers assuming that all other entities always self treat.

PSS = public sewerage system, SEPS = specified environmental preservation public sewerage system, SSW = Statistics of Sewerage Works, WAC = wide-area consolidation.

Table 4 provides the municipal-level detail for 17 municipalities in the subprefectures of West, North, and Central Harima that we have classified as IDWACs. However, unlike the 10 FDWAC municipalities, there is considerably more diversity in the operating characteristics of the IDWAC towns. Thus, within West Harima, we also classify Aioi, Ako, Kamigori, and Sayo as "rural - fragmented self-treaters," as, despite the presence of some relatively large PSS treatment plants, these towns operate a large number of relatively small sewage treatment plants and have no access to RBS treatment. In contrast, despite their small populations, relatively low served density, and high mains 
length per population served, Taishi and Tatsuno are, respectively, $100 \%$ and $88 \%$ reliant on RBS treatment and are therefore classified as "fairly rural - integrated by RBS" municipalities. Shiso, which is $43 \%$ reliant on RBS treatment is classified as a "rural -partially RBS integrated" town. This distinction in characteristics suggests that the objectives of WAC differ somewhat within different parts of West Harima, as Aioi, Ako, Kamigori, and Sayo would benefit from consolidation to improve operational performance without physical integration, while consolidation of the municipal operations of Taishi, Tatsuno, and Shiso with the operations of the Ibogawa RBS system, could yield benefits from consolidation around a non-urban RBS for treatment and collection efficiency. Table 6 therefore suggests the creation of a West Harima Rural PSA and an Ibogawa River PSA within West Harima. As with the suggested legal form for FDWAC consolidation, the West Harima Rural PSA could be established as an operating cooperative owned by its municipal members, thereby allowing retention of municipal control. However, stronger consolidation within a proposed Ibogawa River PSA, would require cooperation and/or consolidation of municipal operations with part of the Hyogo Prefecture River Basin Authority, which operates all RBS plants in the prefecture.

Consideration of North Harima reveals that except for Taka, which we classify as a "rural - fragmented self-treater" municipality, the minimum municipal reliance on RBS treatment from the Kakogawa Downstream RBS system is $73 \%$ and ranges as high as $92 \%$. Although there are 52 small-scale treatment plants in the remaining five North Harima municipalities, we classify them as being "rural - integrated by RBS" municipalities. Thus, in North Harima, consolidation around a non-urban RBS for treatment and collection efficiency would also be an appropriate strategy. Moreover, like the proposed Ibogawa River PSA, the proposed North Harima Subprefecture PSA, would need to coordinate operations of a large number small fragmented treatment plants, despite the vast majority of treatment being carried out within a single currently existing RBS plant in each of these proposed PSAs. This suggests another potential form of consolidation within both West and North Harima, in which the existing collection systems conveying sewage to RBS treatment plants are consolidated with the RBS collection and treatment plants, while the collection and treatment operations of smaller fragmented systems within each subprefecture would be consolidated to improve operational performance without physical integration.

Central Harima subprefecture differs considerably from the other IDWACs because while Fukusaki, Ichikawa, and Kamikawa can be appropriately classified as "rural - fragmented self-treater" municipalities, Himeji has a population of 539,000 . As the city's existing boundaries are the result of the 2005 consolidation of its urban core with more rural municipalities, Himeji is a "significant regional city with non-urban areas." It therefore operates 4 PSS plants serving an average of 103,500 people each, as well as 28 other plants, which only serve an average of 700 people each. Moreover, while Himeji relies on the Ibogawa and Kakogawa RBS system plants for $14 \%$ of its population served, it is mostly self-sufficient in sewage treatment. This suggests that as Himeji already supports a substantial number of sewage treatment plants within its existing municipal boundaries, it might be logical to extend this support by establishment of a Central Harima PSA, with a strategy objective of consolidation around Himeji as a regional champion city to support small municipalities. Since Himeji would clearly dominate any cooperative arrangement given its scale, careful consideration of the governance arrangements is required. 


\section{Table 4: Operating Characteristics of Intermediately Decentralized Wide-Area Consolidation Regions Proposed by the Hyogo Prefecture Government (IDWACs)}

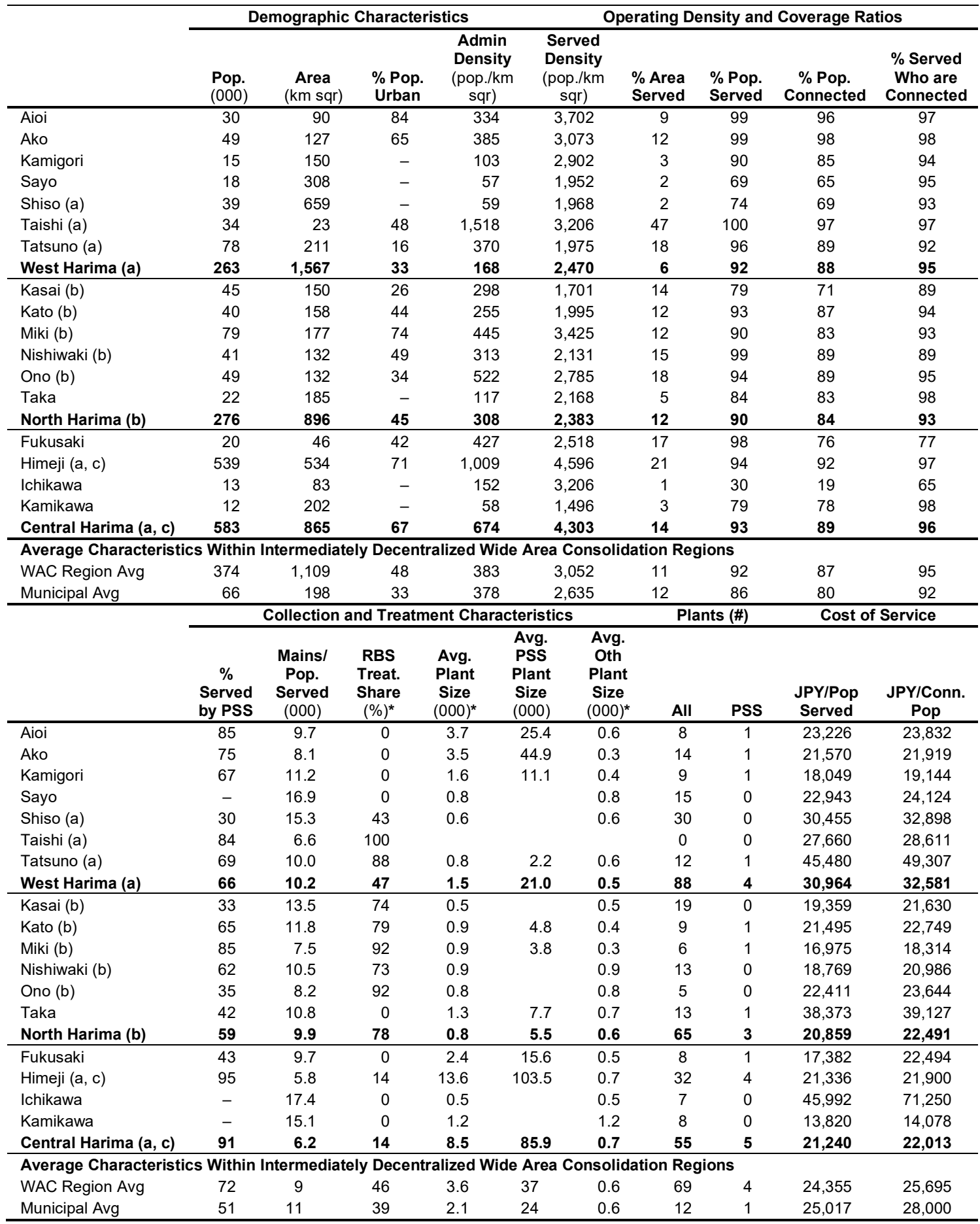

External Treatment by (a) Ibogawa RBS, (b) Kakogawa Upstream RBS. (c) Kakogawa Downstream RBS.

* As data on external treatment is only available for PSS and SEPS's in the SWS database we have calculated these numbers assuming that all other entities always self treat.

PSS $=$ public sewerage system, SEPS = specified environmental preservation public sewerage system, SSW $=$ Statistics of Sewerage Works, WAC = wide-area consolidation 
Table 5 provides the municipal-level detail for 14 municipalities in the subprefectures of East Harima, Kobe, Hanshin South, and Hanshin North, which we have classified as MCWACs. While these subprefectures are characterized by reliance on substantially more centralized sewerage systems, there is a high level of diversity in their organizational arrangement, as well as a high degree of operational fragmentation, given that this region is largely made up of a large urban area in which municipal boundaries are sometimes not discernible when travelling across them. Thus, in the MCWACs, fragmentation of operations can occur for a variety of reasons including historically determined municipal scale and boundaries, municipal decision-making with regard to maintaining autonomy of operations and independence from control from neighboring and/or larger cities, and differences in municipal access to RBS treatment. However, meaningful differences also exist between the WAC regions proposed by Hyogo Prefecture within the overall MCWAC area.

Within East Harima subprefecture, consideration of the operational details provided in Table 5 demonstrates that Akashi is quite distinct from the other municipalities; it is an "urban - fragmented self-treater." By this, we mean that it is part of a larger metropolitan region with high density but has chosen as a modest-sized urban municipality to retain full independence of sewage collection and treatment operations. Harima, Inami, Kakogawa, and Takasogo ${ }^{11}$ all rely heavily on RBS treatment provided by the Kakogawa Downstream RBS plant, but except for Kakogawa are also relatively small municipalities within a larger metropolitan urban area. As detailed in Table 6, consolidation around an urban RBS of all operations and infrastructure is an appropriate objective for WAC for a proposed East Harima Subprefecture PSA. By eliminating fragmentation in municipal decision-making and thereby allowing for increased operational and infrastructure integration across both collection and treatment activities, such consolidation is likely to result in substantial scale economy benefits.

Hanshin North subprefecture stands out as all of its sewage treatment is already carried out in only three RBS treatment plants, with the exception of just over 5,000 people who are served by eight DAG plants in the most rural parts of Sanda. Even though Sanda and Inagawa's population densities are relatively low compared to the rest of Hanshin North, both are functionally linked to the urban core of Hyogo Prefecture and rely almost exclusively on RBS treatment. This suggests that consolidation around an urban RBS of all operations and infrastructure is also the appropriate objective for a potential Hanshin North PSA. However, it is important to emphasize that given the already high integration of sewage treatment in a few large RBS treatment plants, the benefits from consolidation in Hanshin North are likely to derive from operational efficiencies in sewage collection if municipal boundaries within a metropolitan urban area no longer influence decision-making.

11 Takasago is the only city in Hyogo where PSS wastewater is treated by another PSS since part of the wastewater of Takasago in East Harima is treated by Himeji's PSS in Central Harima. 
Table 5: Operating Characteristics of More Centralized Wide-Area Consolidation Regions Proposed by the Hyogo Prefecture Government (MCWACs)

\begin{tabular}{|c|c|c|c|c|c|c|c|c|c|c|}
\hline & \multicolumn{4}{|c|}{ Demographic Characteristics } & \multicolumn{6}{|c|}{ Operating Density and Coverage Ratios } \\
\hline & $\begin{array}{l}\text { Pop. } \\
(000)\end{array}$ & $\begin{array}{c}\text { Area } \\
(\mathrm{km} \text { sqr })\end{array}$ & $\begin{array}{l}\text { \% Pop. } \\
\text { Urban }\end{array}$ & $\begin{array}{c}\text { Admin } \\
\text { Density } \\
\text { (pop./k } \\
\text { m sqr) }\end{array}$ & \multicolumn{2}{|c|}{$\begin{array}{l}\text { Served } \\
\text { Density } \\
\text { (pop./km } \\
\text { sqr) }\end{array}$} & $\begin{array}{l}\% \text { Area } \\
\text { Served }\end{array}$ & $\begin{array}{l}\text { \% Pop. } \\
\text { Served }\end{array}$ & $\begin{array}{c}\% \text { Pop. } \\
\text { Connected }\end{array}$ & $\begin{array}{l}\% \text { Served } \\
\text { Who are } \\
\text { Connected }\end{array}$ \\
\hline Akashi & 299 & 49 & 95 & 6,048 & 7,7 & & 78 & 100 & 98 & 98 \\
\hline Harima (c) & 35 & 9 & 98 & 3,786 & 6,7 & & 55 & 98 & 89 & 92 \\
\hline Inami (c) & 31 & 35 & 44 & 899 & 3,1 & & 28 & 96 & 92 & 96 \\
\hline Kakogawa (c) & 268 & 138 & 81 & 1,933 & 6,3 & & 28 & 91 & 86 & 95 \\
\hline Takasago $(\mathrm{c}, \mathrm{g})$ & 92 & 34 & 96 & 2,689 & 6,4 & & 40 & 95 & 88 & 93 \\
\hline East Harima $(\mathrm{c}, \mathrm{g})$ & 725 & 266 & 88 & 2,722 & 6,5 & & 40 & 96 & 92 & 96 \\
\hline Amagasaki (d) & 463 & 51 & 100 & 9,119 & 11,4 & & 80 & 100 & 100 & 100 \\
\hline Ashiya & 96 & 19 & 100 & 5,156 & 8,6 & & 60 & 100 & 100 & 100 \\
\hline Kobe $(e)$ & 1,529 & 557 & 94 & 2,745 & 8,6 & & 32 & 100 & 100 & 100 \\
\hline Nishinomiya (d, e) & 485 & 100 & 93 & 4,842 & 10,1 & & 48 & 100 & 100 & 100 \\
\hline $\begin{array}{l}\text { Kobe \& Hanshin } \\
\text { South }(d, e)\end{array}$ & 2,572 & 726 & 95 & 3,541 & 9,3 & & 38 & 100 & 100 & 100 \\
\hline Inagawa (f) & 32 & 90 & 77 & 350 & 4,1 & & 8 & 99 & 97 & 99 \\
\hline Itami $(\mathrm{d}, \mathrm{f})$ & 202 & 25 & 100 & 8,037 & 9,9 & & 81 & 100 & 100 & 100 \\
\hline Kawanishi (f) & 159 & 53 & 91 & 2,983 & 8,9 & & 33 & 100 & 99 & 99 \\
\hline Sanda (e) & 113 & 210 & 81 & 539 & 3,7 & & 13 & 92 & 90 & 98 \\
\hline Takarazuka $(\mathrm{d}, \mathrm{f})$ & 234 & 102 & 99 & 2,300 & 9,5 & & 24 & 99 & 98 & 99 \\
\hline $\begin{array}{l}\text { Hanshin North (d, e, } \\
\text { f) }\end{array}$ & 740 & 481 & 94 & 1,539 & 7,4 & & 20 & 98 & 97 & 99 \\
\hline \multicolumn{11}{|c|}{ Average Characteristics Within More Centralized Wide Area Consolidation Regions } \\
\hline WAC Region Avg & 1,346 & 491 & 92 & 2,601 & 7,7 & & 33 & 98 & 96 & 98 \\
\hline \multirow[t]{3}{*}{ Municipal Avg } & 288 & 105 & 89 & 3,673 & 7,5 & & 43 & 98 & 96 & 98 \\
\hline & \multicolumn{6}{|c|}{ Collection and Treatment Characteristics } & \multicolumn{2}{|c|}{ Plants (\#) } & \multicolumn{2}{|c|}{ Cost of Service } \\
\hline & $\begin{array}{c}\% \\
\text { Served } \\
\text { by PSS }\end{array}$ & $\begin{array}{l}\text { Mains/ } \\
\text { Pop. } \\
\text { Served } \\
(000) \\
\end{array}$ & $\begin{array}{c}\text { RBS } \\
\text { Treat. } \\
\text { Share } \\
(\%)^{*} \\
\end{array}$ & $\begin{array}{l}\text { Avg. } \\
\text { Plant } \\
\text { Size } \\
(000)^{*}\end{array}$ & $\begin{array}{l}\text { Avg. } \\
\text { PSS } \\
\text { Plant } \\
\text { Size } \\
(000) \\
\end{array}$ & $\begin{array}{c}\text { Avg. } \\
\text { Oth } \\
\text { Plant } \\
\text { Size } \\
(000)^{*}\end{array}$ & t & PSS & $\begin{array}{l}\text { JPY/Pop } \\
\text { Served }\end{array}$ & $\begin{array}{l}\text { JPY/Conn. } \\
\text { Pop }\end{array}$ \\
\hline Akashi & 100 & 3.0 & 0 & 74.3 & 74.3 & & 4 & 4 & 13,519 & 13,760 \\
\hline Harima (c) & 100 & 3.9 & 100 & & & & 0 & 0 & 13,550 & 14,777 \\
\hline Inami (c) & 57 & 9.8 & 84 & 0.6 & & 0.6 & 8 & 0 & 14,809 & 15,377 \\
\hline Kakogawa (c) & 96 & 4.2 & 99 & 1.5 & & 1.5 & 2 & 0 & 13,902 & 14,705 \\
\hline Takasago $(\mathrm{c}, \mathrm{g})$ & 100 & 4.2 & 52 & 21.2 & 21.2 & & 2 & 2 & 10,151 & 10,970 \\
\hline East Harima $(\mathbf{c}, \mathbf{g})$ & 97 & 3.9 & 50 & 21.7 & 56.6 & 0.8 & 16 & 6 & 13,284 & 13,865 \\
\hline Amagasaki (d) & 100 & 2.3 & 55 & 103.2 & 103.2 & & 2 & 2 & 8,943 & 8,982 \\
\hline Ashiya & 100 & 2.6 & 0 & 47.9 & 47.9 & & 2 & 2 & 11,725 & 11,725 \\
\hline Kobe $(e)$ & 98 & 2.9 & 9 & 44.8 & 229.2 & 0.5 & 31 & 6 & 13,095 & 13,106 \\
\hline Nishinomiya (d, e) & 100 & 2.1 & 23 & 123.7 & 123.7 & & 3 & 3 & 10,884 & 10,911 \\
\hline $\begin{array}{l}\text { Kobe \& Hanshin } \\
\text { South }(d, e)\end{array}$ & 99 & 2.6 & 20 & 54.3 & 157.6 & 0.5 & 38 & 13 & 11,881 & 11,901 \\
\hline Inagawa (f) & 78 & 6.3 & 100 & & & & 0 & 0 & 15,543 & 15,765 \\
\hline Itami $(d, f)$ & 100 & 2.3 & 100 & & & & 0 & 0 & 10,282 & 10,319 \\
\hline Kawanishi (f) & 100 & 3.1 & 100 & & & & 0 & 0 & 7,193 & 7,242 \\
\hline Sanda (e) & 88 & 5.3 & 95 & 0.7 & & 0.7 & 8 & 0 & 9,716 & 9,919 \\
\hline Takarazuka $(\mathrm{d}, \mathrm{f})$ & 100 & 2.2 & 100 & & & & 0 & 0 & 11,593 & 11,702 \\
\hline $\begin{array}{l}\text { Hanshin North (d, e, } \\
\text { f) }\end{array}$ & 97 & 3.0 & 99 & 0.7 & & 0.7 & 8 & 0 & 10,169 & 10,261 \\
\hline \multicolumn{11}{|c|}{ Average Characteristics Within More Centralized Wide Area Consolidation Regions } \\
\hline WAC Region Avg & 98 & 3.2 & 56 & 25.5 & 107.1 & 0.7 & 20.7 & 6.3 & 11,778 & 12,009 \\
\hline Municipal Avg & 94 & 3.9 & 66 & 46.4 & 99.9 & 0.8 & 4.4 & 1.4 & 11,779 & 12,090 \\
\hline
\end{tabular}

External Treatment by (c) Kakogawa Downstream RBS, (d) Mukogawa Downstream RBS, (e) Mukogawa Upstream RBS, (f) Inagawa RBS, (g) Himeji PSS.

* As data on external treatment is only available for PSS and SEPS's in the SWS database we have calculated these numbers assuming that all other entities always self treat.

We finally consider the proposed WAC region consisting of Kobe and the three cities of Amagaski, Ashiya, and Nishinomiya that make up Hanshin South. This area is dominated by the city of Kobe, which despite its large rural fringe, is the key part of Hyogo Prefecture's urban core. With populations in excess of 400,000 both Amagasaki and Nishinomiya would be considered to be relatively large cities in other prefectures but are 
dwarfed by Kobe. Ashiya is similarly part of this urban core, but its population is only 96,000 . Finally, within this region, substantial diversity exists in treatment options employed, with Ashiya relying only on its own PSS treatment plants, and Kobe relying predominantly on PSS treatment and relatively little RBS treatment in its urban core, while Nishinomiya and Amagasaki rely on RBS treatment for $23 \%$ and $55 \%$, respectively, of their treatment needs. However, because of the dominance of Kobe, RBS plants only provide $20 \%$ of all treatment in Kobe and Hanshin South. This relatively low RBS treatment share, coupled with the potential rivalry between the region's relatively large municipalities, means that overcoming existing municipal barriers to increased cooperation is a key issue to facilitate WAC. However, the current fragmentation in the operation and management of large cities based on municipal boundaries within a metropolitan urban area suggests that pursuing urban consolidation of operations, collection and treatment infrastructure via a Kobe and Hanshin South PSA could yield substantial efficiencies and scale economies. Moreover, while these cities currently do not coordinate their sewage treatment and collection operations, the example of Hanshin Bulk Water Supply Authority, which is a cooperative jointly owned by Kobe, Amagaski, Ashiya, Nishinomiya, and Takarazuka, is a successful local example that could be emulated to improve the efficiency of sewerage services.

\section{DISCUSSION OF PROPOSED PUBLIC SEWER AUTHORITIES TO IMPLEMENT WIDE-AREA CONSOLIDATION}

Table 6 summarizes our conclusions from the previous section with regard to the sewerage system characteristics in each of the municipalities and also includes our suggestion with regard to the primary strategy objective(s) in each of the WAC regions proposed by Hyogo Prefecture. Moreover, it further includes our suggestion for the creation of new proposed PSAs that we believe would be necessary to achieve meaningful benefits from WAC. We therefore focus further on our reasons for proposing new PSAs, before discussing the proposals in Table 6 for FDWACS, IDWACs, and MCWACs.

We are proposing new PSAs because, while the system of municipally controlled sewerage services may have been appropriate in an earlier period of high economic growth, it is now a potentially strong barrier to improving the resilience and cost-effectiveness of sewerage systems in the face of rapid population decline and constrained public budgets. Thus, during Japan's era of both rapid public and economic growth, generous central government subsidies aimed at expanding sewerage services coupled with extremely localized decision-making could effectively target resources to satisfy local needs. Moreover, as the expansion of sewerage services to improve public health and the environment was the primary policy goal, local governments were probably best placed to identify citizens and areas that should be targeted for connection to newly established sewerage networks using central government-subsidized investment. However, Japan's current policy context requires a switch in primary focus to cost-effectiveness and retaining system resilience in the face of population decline. 
Table 6: Proposed Public Sewer Authorities and Details of Their Objectives

\begin{tabular}{|c|c|}
\hline $\begin{array}{l}\text { Proposed Wide-Area } \\
\text { Consolidation Entity and } \\
\text { Constituent Municipalities }\end{array}$ & $\begin{array}{l}\text { Municipal Characteristics/Objectives } \\
\text { for Proposed Wide-Area Consolidation }\end{array}$ \\
\hline Tajima Subprefecture PSA & $\begin{array}{l}\text { Consolidation to improve operational performance without } \\
\text { physical integration }\end{array}$ \\
\hline Asago & rural - fragmented self-treater \\
\hline Kami & rural - fragmented self-treater \\
\hline Shinonsen & rural - fragmented self-treater \\
\hline Toyooka & rural - fragmented self-treater \\
\hline Yabu & rural - fragmented self-treater \\
\hline Tamba Subprefecture PSA & $\begin{array}{l}\text { Consolidation to improve operational performance without } \\
\text { physical integration }\end{array}$ \\
\hline Tamba & rural - fragmented self-treater \\
\hline Tambasasayama & rural - fragmented self-treater \\
\hline Awaji Subprefecture PSA & $\begin{array}{l}\text { Consolidation to improve operational performance without } \\
\text { physical integration }\end{array}$ \\
\hline Awaji & rural - fragmented self-treater \\
\hline Minamiawaji & rural - fragmented self-treater \\
\hline Sumoto & rural - fragmented self-treater \\
\hline West Harima Rural PSA & $\begin{array}{l}\text { Consolidation to improve operational performance without } \\
\text { physical integration }\end{array}$ \\
\hline Aioi & rural - fragmented self-treater \\
\hline Ako & rural - fragmented self-treater \\
\hline Kamigori & rural - fragmented self-treater \\
\hline Sayo & rural - fragmented self-treater \\
\hline Ibogawa River PSA & $\begin{array}{l}\text { Consolidation around non-urban RBS for treatment and collection } \\
\text { efficiency }\end{array}$ \\
\hline Shiso (a) & rural - partially RBS integrated \\
\hline Taishi (a) & fairly rural - integrated by RBS \\
\hline Tatsuno (a) & fairly rural - integrated by RBS \\
\hline $\begin{array}{l}\text { North Harima } \\
\text { Subprefecture PSA }\end{array}$ & $\begin{array}{l}\text { Consolidation around non-urban RBS for treatment and collection } \\
\text { efficiency }\end{array}$ \\
\hline Kasai (b) & rural - integrated by RBS \\
\hline Kato (b) & rural - integrated by RBS \\
\hline Miki (b) & rural - integrated by RBS \\
\hline Nishiwaki (b) & rural - integrated by RBS \\
\hline Ono (b) & fairly rural - integrated by RBS \\
\hline Taka & rural - fragmented self-treater \\
\hline Central Harima PSA $(a, c)$ & $\begin{array}{l}\text { Consolidation around regional champion city to support small } \\
\text { municipalities }\end{array}$ \\
\hline Fukusaki & rural - fragmented self-treater \\
\hline Himeji $(a, c)$ & regional city with non-urban areas \\
\hline Ichikawa & rural - fragmented self-treater \\
\hline Kamikawa & rural - fragmented self-treater \\
\hline
\end{tabular}


Table 6 continued

\begin{tabular}{|c|c|}
\hline $\begin{array}{l}\text { Proposed Wide-Area } \\
\text { Consolidation Entity and } \\
\text { Constituent Municipalities }\end{array}$ & $\begin{array}{l}\text { Municipal Characteristics/Objectives } \\
\text { for Proposed Wide-Area Consolidation }\end{array}$ \\
\hline $\begin{array}{l}\text { East Harima Subprefecture } \\
\text { PSA }\end{array}$ & $\begin{array}{l}\text { Consolidation around urban RBS of all operations and } \\
\text { infrastructure }\end{array}$ \\
\hline Akashi & urban - fragmented self-treater \\
\hline Harima (c) & $\begin{array}{l}\text { urban small city - RBS treated, benefits from cooperation in collection } \\
\text { operations }\end{array}$ \\
\hline Inami (c) & urban small city - RBS treated, but small for collection operations \\
\hline Kakogawa (c) & urban - fully RBS treated except for rural fringe \\
\hline Takasago (c, g) & urban small city- RBS treated, but small for collection operations \\
\hline $\begin{array}{l}\text { Kobe \& Hanshin South } \\
\text { PSA }\end{array}$ & $\begin{array}{l}\text { Urban consolidation of operations, collection, and treatment } \\
\text { infrastructure }\end{array}$ \\
\hline Amagasaki (d) & urban core - concern with losing control to Kobe/low cost benefit \\
\hline Ashiya & urban - fragmented self-treater \\
\hline Kobe (e) & urban core large city but with large rural fringe \\
\hline Nishinomiya (d, e) & urban core - concern with losing control to Kobe/low cost benefit \\
\hline Hanshin North PSA & $\begin{array}{l}\text { Consolidation around urban RBS of all operations and } \\
\text { infrastructure }\end{array}$ \\
\hline Inagawa (f) & urban core - fully RBS treated - small for collection operations \\
\hline Itami $(d, f)$ & $\begin{array}{l}\text { urban core - fully RBS treated - medium size but benefits from full } \\
\text { consolidation }\end{array}$ \\
\hline Kawanishi (f) & $\begin{array}{l}\text { urban core - fully RBS treated -medium size but benefits from full } \\
\text { consolidation }\end{array}$ \\
\hline Sanda (e) & $\begin{array}{l}\text { functionally linked to urban core - fully RBS treated except for rural } \\
\text { fringe }\end{array}$ \\
\hline Takarazuka $(\mathrm{d}, \mathrm{f})$ & $\begin{array}{l}\text { urban core - fully RBS treated -medium size but benefits from full } \\
\text { consolidation }\end{array}$ \\
\hline
\end{tabular}

PSA = public sewer authority, RBS = river basin system .

Note: (a)-(g) stands for the external treatment by (a) Ibogawa RBS, (b) Kakogawa Upstream RBS, (c) Kakogawa Downstream RBS, (d) Mukogawa Downstream RBS, (e) Mukogawa Upstream RBS, (f) Inagawa RBS, and (g) Himeji PSS.

Source: Authors.

If achieving cost-effectiveness will require collaboration across municipal and entity boundaries, fragmented municipal control and political decision-making are likely to hinder it. Thus, it is likely that informal collaboration and cooperation between municipalities and entities will be hindered by governance issues, unless formal collaboration arrangements are put in place. Furthermore, if the goal is to achieve cost-effective and resilient services including maintaining service provision in rural areas where population decline is most severe, municipal control may result in parochial decision-making that will hinder the provision of cost-effective sewerage services to all citizens of Hyogo Prefecture. If decision-makers are limited to a municipal focus, they would not have any reason or incentive to consider regional solutions and alternatives, as such solutions are, by definition, outside their mandate. In contrast, an entity responsible for a larger region can consider the relative merits of localized and more centralized solutions, and thereby choose the best solution to optimize total regional costs and service levels. Finally, a regional entity with a policy mandate to reduce costs, maintain services, and improve the share of costs recovered from tariffs could, for example, set uniform tariffs and thereby cross-subsidize service in high-cost areas. 
In our opinion, the establishment of regional PSAs that encompass all entity types would also address the fragmentation of policy and subsidy regimes given that different Japanese government ministries are responsible for oversight of different sewerage systems. Even though municipalities currently manage all the entities within their boundaries, separate data are reported for each entity, and tariff and subsidy arrangements differ based on entity type. Particularly in rural regions where municipalities have established multiple sewerage entities, as originally required to receive investment subsidy for different customer types and areas, competing government policy objectives and the incentives of municipal decision-makers responding to those objectives could result in suboptimal outcomes. In contrast, a single regional (or municipal) authority responsible for managing all sewerage systems, coupled with reformed and unified central government regulation and subsidy regimes, would simplify decision-making. This would, for example, better allow the consolidation of operations across different entity types if this were cost-effective. Moreover, an entity that is responsible for providing the most cost-effective wastewater services to all citizens, rather than to certain types of citizens, should, in principle, better evaluate the cost-benefit tradeoff between sewered and non-sewered wastewater management solutions, and thereby help to reduce what appear to be current incentives to overinvest in underutilized rural sewerage systems.

We finally note that while sewerage services are primarily a municipal responsibility in Japan, there is considerable precedent favoring consolidation to a higher level. While we in no way propose full municipal consolidation to achieve WAC in sewage systems, the municipal consolidations set a clear precedent to improve performance and cost-effectiveness. Moreover, the establishment of prefecture-owned and -operated RBS authorities to provide sewage treatment services provides another important and widely used example of super-municipal control and organization within the Japanese sewerage industry itself. Furthermore, while only 18 cooperative sewerage entities operate in Japan, these multiple municipal operating entities suggest that the current legal organizational arrangement could be employed to allow consolidation via cooperative ownership and/or operation of sewerage facilities. As many Japanese municipalities, including those served by the abovementioned Hanshin Bulk Water Supply Authority, are members of bulk water supply cooperatives or receive water supply from a prefecture-owned bulk water supply authority, the water supply industry also provides ample examples of existing super-municipal organization in a related industry. Thus, municipally owned operating cooperatives and/or transferring ownership and operation of sewage systems to prefecture-controlled entities are two alternative and wellestablished organizational forms that could be employed to establish the regional PSAs that we believe are necessary to enable effective WAC.

Given this discussion of potential governance and institutional arrangements for the proposed PSAs, we now review the rationale and objectives that we have proposed for them. At the top of Table 6, we first summarize the four proposed regional PSAs that we suggest should follow an objective of consolidation to improve operational performance without physical integration. The four include the three proposed Tajima, Tamba, and Awaji Subprefecture PSAs, which are identical to the prefecture's proposed WAC regions classified as FDWACs. They also include our proposed West Harima Rural PSA, which forms only part of the West Harima WAC region that we classified as an IDWAC. In these proposed PSAs, all municipalities are classified as "rural - fragmented self-treaters." Thus, physical scaling of their facilities to increase their productivity is not feasible, because sewerage systems are very small and geographically isolated, and, by similar logic, interconnection between systems is 
probably not economically feasible. Moreover, low total population served in each municipality suggests that they will further suffer higher average costs because of indivisible input costs associated with managerial, accounting, engineering, technical, and outsourcing activities that are only employed at the scale of a single small municipality. By establishing a regional PSA, efficiencies can be achieved by centralizing these activities in a larger entity and reorganizing maintenance activities to reduce overall costs. As no existing municipality or entity within these proposed PSA areas has sufficient scale, capacity, or capability that can be developed to facilitate WAC, we believe the case for establishing such new regional PSAs is particularly strong.

As summarized in Table 6, both the proposed Ibogawa River PSA and the proposed North Harima Subprefecture PSA are associated with an objective of consolidation around a non-urban RBS for treatment and collection efficiency. This builds from the potential managerial capacity associated with the Ibogawa and Kakogawa Upstream RBS sewerage systems that respectively provide the vast majority of sewage treatment in the two proposed PSA areas. Despite the high degree of RBS treatment, these RBS systems are the smallest in Hyogo and have high unit costs, which may be associated with relatively low scale of their plants but also high sewage collection costs given low population density in these regions. Furthermore, a substantial number of small fragmented sewerage systems also exist, as there are 42 and 65 relatively small nonRBS treatment plants, respectively, in these two proposed PSAs. As a result, the proposed PSAs would also likely benefit from an approach similar to that proposed for the Tajima, Tamba, and Awaji Subprefecture PSAs and the West Harima Rural PSA. Moreover, the relatively small populations of all the constituent municipalities strongly suggest that centralization of indivisible activities in a regional PSA could result in substantial operational efficiencies; for example, all sewage collection and a substantial portion of sewage treatment is managed and operated by small municipalities.

The presence of Himeji allows us to propose that a Central Harima PSA should pursue a strategy of consolidation around a regional champion city to support small municipalities. The organizational logic for this PSA clearly flows from the fact that with a population of 539,000 , Himeji alone has almost twice the scale of the largest of the six proposed PSAs we have already discussed. As a result, it should have the scale and resources to provide leadership within the PSA. However, given that Himeji itself contains a large rural fringe with a significant number of small fragmented sewage plants and that the three other municipalities making up the proposed PSA region are extremely small "rural - fragmented self-treaters," achieving the benefits from consolidation will in all likelihood require similar operational changes to those we envision within the FDWAC and IDWAC regions. Himeji's high costs of service, despite its large population, suggest that, while consolidation may improve costs, underlying operating characteristics related to relatively low population densities and fragmentation of population settlements may create a floor below which costs cannot fall.

Our discussion of the MCWACs and the summary in Table 6 suggest a contrary conclusion for the proposed East Harima Subprefecture PSA, Kobe and Hanshin South PSA, and Hanshin North PSA, where high population densities have enabled the consolidation of sewage treatment in large plants, low sewer mains per population served, and the lowest observed costs of service in Hyogo Prefecture. Nevertheless, this highly urbanized metropolitan area still suffers from substantial fragmentation. This is because the municipal organization of sewage management may prevent stronger physical integration of operations, collection, and/or treatment infrastructure across municipal boundaries. 
While Hanshin North's 99\% reliance on only three RBS treatment plants means that it would be difficult to further consolidate sewage treatment, regional rather than municipal management of sewage collection could potentially result in substantial operational and contracting efficiencies. Similarly, regional coordination of East Harima's sewage activities could also achieve operational efficiencies in sewage collection. However, regional planning by a PSA, aimed at optimizing regional sewage collection and treatment costs via reconfiguration of and optimization of existing municipal collection networks and RBS and PSS treatment plants, could also potentially yield substantial cost savings in East Harima. For example, this might occur if integrating Akashi's currently fully independent sewerage system into an optimized regional system made a reduction in overall regional costs feasible. Similar reasoning applies for Kobe and Hanshin South, where at least three very large independent cities exist, but they do not coordinate sewage collection and treatment activities across their boundaries.

It is highly likely that municipal decision-making in each of the MCWACs prevents the potential and incentives for regional optimization that would exist within a regional PSA. We note the example of Tokyo's 23 wards, where a large metropolitan area is governed by a single government entity and hence a single PSS entity coordinates sewerage activities while achieving very low costs of operation. In contrast, while London, England is actually comprised of 32 independent boroughs responsible for the delivery of most municipal services, Thames Water is a single entity responsible for coordinating all water and sewage-related activities in Greater London and its surrounding suburban and rural areas. We therefore believe that the creation of a regional PSAs may be an essential precondition if existing municipally defined barriers to cooperation and sewage system optimization in highly urbanized areas cannot be otherwise overcome.

\section{SUMMARY AND FUTURE RESEARCH TO INFORM WIDE-AREA CONSOLIDATION POLICY}

This paper has sought to evaluate the appropriateness of the WAC regions that were recently proposed by Hyogo Prefecture. By characterizing sewerage system operations in each of these regions, our study also aims to provide a preliminary understanding of the factors that influence performance. As physical, operational, entity, and municipal fragmentation of a system have all been revealed as key factors influencing performance, we have argued for the potential benefits of establishing regional PSAs to facilitate effective WAC. By consolidating ownership with operational and political decision-making for sewerage systems, PSAs will be well placed to develop, implement, and control effective strategies to improve the resilience, the cost, and the service performance of the sewerage systems they manage. While we strongly urge both Hyogo Prefecture and the Government of Japan to consider policy changes that effectively shift primary responsibility for sewerage systems from the municipal to a regional level, we also caution that the appropriateness and design of such policies need to be informed with further research before any move to implementation. We therefore identify an urgent need for research in four discrete but interrelated areas.

First, appropriate benchmarking and cost modelling of the Japanese sewerage industry is required. Moreover, such modelling must grapple with how the complex physical, operational, entity, and municipal fragmentation of the system and how it influences costs. Rather than focusing on a subsample of entity types to simplify the research problem, appropriate research that will provide meaningful and reliable conclusions that policy makers should act on requires difficult data handling and quantitative 
modelling that can capture the cost implications associated with the system complexity we have tried to illustrate in this paper. Moreover such models must be carefully designed to distinguish between operating characteristics such as settlement patterns and physical geography that are outside of managerial control and therefore legitimately influence costs, other factors such as poor management, as well as institutional and organizational factors that cause costs to be higher because of inefficiency. Such research would also help better identify the relationship between scale and organizational forms, but also how scale economies in the sewerage industry are influenced by physical factors such as the density and fragmentation of settlement within a given operating area, as well as when it is feasible to achieve scale benefits through shared operations even if physical integration is not feasible.

Second, given that Great Heisei Era Consolidation of municipalities effectively consolidated the ownership, operation, and management of sewerage systems that were previously controlled by separate municipalities, research should be conducted with regard to whether and how such consolidation influenced the performance of the sewerage industry. Thus, the theoretical methodology employed in Arocena et al. (2020) concludes that, on average, municipal consolidation itself improved the productivity of water supply in a sample of merged Japanese municipalities. Similar research should be carried out for Great Heisei Era Consolidation of the sewerage industry. We note, however, that the substantially greater prevalence of entity and sewage treatment plant fragmentation, as well as external treatment of sewage by RBSs, present important policy-relevant modelling challenges relative to the approach taken by Arocena et al. (2020) for the Great Heisei Era Consolidation of water supply. Moreover, to make this research more relevant for policy makers, it should be designed to not only measure whether past mergers can be associated with productivity improvement, but to also better explain why they were and what types of municipal mergers and merger strategies improved performance.

Third, while analysis of the Great Heisei Era Consolidation of the sewerage industry can provide important insights with regard to whether consolidation can improve performance, such ex post research is not sufficient, as policy makers need to make informed ex ante decisions with regard to the potential benefits of alternative proposed consolidations. We therefore note the extensive literature on the potential benefits of mergers building from the seminal contribution by Bogetoft and Wang (2005). However, we emphasize that, to our knowledge, this literature has not grappled with the implications of the geographically determined production relationships that we have illustrated to be important in the Japanese sewerage industry. If consolidation occurs between entities that operate multiple physically distinct sewerage systems, both the presence of and differences in multisystem production must be accounted for in the model. The models must also allow for and capture the potential feasibility of systemlevel consolidation after a merger. Such well-specified models would confirm or refute the implicit assumptions and implications in our analysis by, for example, supporting our assumption that physical integration of systems would be difficult in FDWAC regions but more feasible in IDWAC and MCWAC regions. Also, to our knowledge, the literature has also not yet provided a tested methodology with which to test the potential benefits of mergers between partially or fully vertically separated entities such as PSSs and RBSs. Japanese policy makers would also be well served by the development of empirically tested models that account for external treatment of sewage when assessing the potential benefits of mergers.

Finally, we emphasize the need for more careful study of how entity governance and accountability, organizational forms, government regulation, and institutions influence 
the performance of the Japanese sewerage industry, and how changes in these factors may have competing impacts on different performance factors and stakeholders. The implicit assumption in our discussion is that the establishment of PSAs is appropriate because the cost (benefits) of local political control of sewerage systems is likely to be substantially greater (smaller) than the potential gains from improving resilience and operational efficiency via consolidation at the regional level. Our opinions with regard to this are heavily influenced by the experience of England and Wales, where in the early 1970s, over 1,000 highly fragmented locally controlled publicly owned sewage and water entities were consolidated into 10 publicly owned and operated regional water authorities, which were subsequently privatized in 1989, while still operating over 6,300 distinct sewage treatment plants in 2020. Saal and Parker (2001) also found that the publicly owned regional entities achieved considerably higher annual productivity growth in the 5 years before privatization than they did in the 10 years after privatization, thereby suggesting that regionalization of decision-making as opposed to privatization may have been a principle source of the productivity gains. In contrast, their study finds that capital investment was significantly greater after privatization, as possible underfunding of capital needs under public ownership was replaced by a regulatory regime that incentivized private investment in the industry. We primarily raise this example because it suggests that careful further study of international differences in the organization of water and sewerage services is likely to provide important insights to Japanese policy makers with regard to different potential approaches to consolidation, as well as the potential benefits and pitfalls that may be associated with them.

In sum, our analysis of the operating characteristics within Hyogo Prefecture's proposed WAC regions suggests that there are strong potential benefits from WAC but that capturing those benefits will require substantial reorganization of the industry. Our preliminary assessment is that operational, managerial, and political control will need to be raised to the regional level consistent with the level of consolidation required to achieve cost and service improvements. As a result, the continuation of the currently municipally controlled system is likely to hamper efforts to achieve meaningful benefits from WAC, therefore suggesting the need for the creation of regional PSAs. As we have detailed in this concluding section, substantial further research is required to not only better support these preliminary conclusions but also to appropriately inform any realworld implementation of WAC in Hyogo Prefecture and more widely in Japan. Furthermore, the real-world implementation of WAC will ultimately require a balanced economic cost-benefit analysis and the resulting "optimal consolidation policies" against other factors. Political, institutional, and governance issues may ultimately affect the optimal organizational structure for the sewerage industry, if the optimization is based solely on economic and engineering considerations. 


\section{REFERENCES}

Aida, K., W.W. Cooper, J.T. Pastor, and T. and Sueyoshi. 1998. Evaluating Water Supply Services in Japan with RAM: A Range-Adjusted Measure of Inefficiency. Omega. 26 (2). pp. 207-32.

Arocena, P., D.S. Saal, T. Urakami, and M. Zschille. 2020. Measuring and Decomposing Productivity Change in the Presence of Mergers. European Journal of Operational Research. 282 (1). pp. 319-33.

Blaeschke, F., and P. Haug. 2018. Does Intermunicipal Cooperation Increase Efficiency? A Conditional Metafrontier Approach for the Hessian Wastewater Sector. Local Government Studies. 44 (1). pp. 151-71.

Bogetoft, P., and D. Wang. 2005. Estimating the Potential Gains from Mergers. Journal of Productivity Analysis. 23 (2). pp. 145-71.

Carvalho, P., R.C. Marques, and S. Berg. 2012. A Meta-regression Analysis of Benchmarking Studies on Water Utilities Market Structure. Utilities Policy. 21. pp. 40-9.

Castellet-Viciano, L., D. Torregrossa, and F. Hernández-Sancho. 2018. The Relevance of the Design Characteristics to the Optimal Operation of Wastewater Treatment Plants: Energy Cost Assessment. Journal of Environmental Management. 222. pp. 275-83.

Forestry Agency. Forest Rate and Planted Forest Rate by Prefecture (FY2016) (Todofukenbetsu-Shinrinritsu-Jinkorinritsu; in Japanese). https://www.rinya.maff.go.jp/j/keikaku/genkyou/h29/1.html (accessed 26 February 2021).

Fraas, A.G., and V.G. Munley. 1984. Municipal Wastewater Treatment Cost. Journal of Environmental Economics and Management. 11 (1). pp. 28-38.

Fraquelli, G., and R. Giandrone. 2003. Reforming the Wastewater Treatment Sector in Italy: Implications of Plant Size, Structure, and Scale Economies. Water Resources Research. 39 (10).

Fuentes, R., T. Torregrosa-Martí, and F. Hernández-Sancho. 2017. Productivity of Wastewater Treatment Plants in the Valencia Region of Spain. Utilities Policy. 46. pp. 58-70.

Guerrini, A., G. Romano, C. Leardini, and M. Martini. 2015. Measuring the Efficiency of Wastewater Services through Data Envelopment Analysis. Water Science and Technology. 71 (12). pp. 1845-51.

Guerrini, A., G. Romano, F. Mancuso, and L. Carosi. 2016. Identifying the Performance Drivers of Wastewater Treatment Plants through Conditional Order-m Efficiency Analysis. Utilities Policy. 42. pp. 20-31.

Hernández-Sancho, F., M. Molinos-Senante, and R. Sala-Garrido. 2011. Cost Modelling for Wastewater Treatment Processes. Desalination. 268 (1-3). pp. 1-5.

Hyogo Prefectural Land Maintenance Department, Public Works Bureau, Sewer Section, Hyogo Prefecture Sewerage Plan (Hyogoken-Gesuido-Keikakuzu). https://web.pref.hyogo.lg.jp/ks16/wd18_000000049.html (accessed 20 January 2020) (in Japanese). 
International Monetary Fund. 2019. World Economic Outlook Database, October 2019. https://www.imf.org/external/pubs/ft/weo/2019/02/weodata/index.aspx (accessed 14 January 2020).

Japan Meteorological Agency. https://www.data.jma.go.jp/obd/stats/data/en/ normal/normal.html

Knapp, M.R.J. 1978. Economies of Scale in Sewage Purification and Disposal. Journal of Industrial Economics. 27 (2). pp. 163-83.

Kobayashi, K., Y. Kitano, H. Watanabe, and M. Ishikawa. 2004. Cost Efficiency Evaluation of Wastewater Disposal Systems (Gesuido System no Hiyo Kouritsusei Hyokahou). Proceedings of JSCE (Doboku Gakkai Ronbunsyu). 751. pp. 111-25. (in Japanese).

Liu, J., and M. Fukushige. 2020. Efficiency and Pricing of Water Supply and Sewerage Services in Japan. Utilities Policy. 62.

Ministry of Internal Affairs and Communication. The Data Collection of Great Heisei Era Consolidation (Shichoson Gappei Shiryosyu). https://www.soumu.go.jp/gapei/ gapei.html (accessed 14 January 2020). (in Japanese).

Mizutani, F., and T. Urakami. 2001. Identifying Network Density and Scale Economies for Japanese Water Supply Organizations. Papers in Regional Science. 80 (2). pp. 211-30.

Molinos-Senante, M., F. Hernandez-Sancho, and R. Sala-Garrido. 2014. Benchmarking in Wastewater Treatment Plants: A Tool to Save Operational Costs. Clean Technologies and Environmental Policy. 16 (1). pp. 149-61.

Molinos-Senante, M., F. Hernández-Sancho, M. Mocholí-Arce, and R. Sala-Garrido. 2016. Productivity Growth of Wastewater Treatment Plants - Accounting for Environmental Impacts: A Malmquist-Luenberger Index Approach. Urban Water Journal. 13 (5). pp. 476-85.

Nakamura, E., T. Urakami, and K. Kakamu. 2019. A Bayesian Stochastic Frontier Model with Endogenous Regressors: An Application to the Effect of Division of Labor in Japanese Water Supply Organizations. Topics in Identification, Limited Dependent Variables, Partial Observability, Experimentation, and Flexible Modeling: Part B. Advances in Econometrics. 40. pp. 29-46.

Nakayama, N. 2001. The Cost Structure of the Japanese Sewage System (Gesuido Jigyo no Hiyo Kozo). Journal of Public Utility Economics (Koeki Jigyo Kenkyu). 2 (53). pp. 23-31 (in Japanese).

Regional Policy Statistics Study Group (Chiiki Seisaku Tokei Kenkyukai). Hyogo prefecture blank map data (Hyogoken Shirochizu Data). https://web.pref.hyogo.lg.jp/kk11/jinkou-tochitoukei/jinkoubunseki.html, (accessed 20 January 2020). (in Japanese).

Renzetti, S. 1999. Municipal Water Supply and Sewage Treatment: Costs, Prices, and Distortions. Canadian Journal of Economics. 32 (3). pp. 688-704.

Saal, D.S., and D. Parker. 2001. Productivity and Price Performance in the Privatized Water and Sewerage Companies of England and Wales. Journal of Regulatory Economics. 20 (1). pp. 61-90.

Saal et al. 2013. Scale and Scope Economies and the Efficient Vertical and Horizontal Configuration of the Water Industry: A Survey of the Literature. Review of Network Economics, 12(1): 93-129. https://doi.org/10.1515/rne-2012-0004 
Terada, M. 2003. Applicability of Data Envelopment Analysis (DEA) for Sewer Enterprise Estimation (Gesuido Jigyo Hyoka ni okeru Oourakusen Bunsekiho (DEA) Tekiyo Kanousei). Doshisha University Policy \& Management (Doshisha Seisaku Kagaku Kenkyu). 4 (1). pp. 123-42 (in Japanese).

Urakami, T. 2007. Economies of Vertical Integration in the Japanese Water Supply Industry. Jahrbuch für Regionalwissenschaft. 27 (2). pp. 129-41.

Urakami, T., and D. Parker. 2011. The Effects of Consolidation amongst Japanese Water Utilities: A Hedonic Cost Function Analysis. Urban Studies. 48 (13). pp. 2805-25. 